University of Louisville

ThinkIR: The University of Louisville's Institutional Repository

Electronic Theses and Dissertations

$1-1927$

\title{
Some philosophical implications of behaviorism.
}

Harold Wayland Tribble

University of Louisville

Follow this and additional works at: https://ir.library.louisville.edu/etd

Part of the Philosophy Commons, and the Psychology Commons

\section{Recommended Citation}

Tribble, Harold Wayland, "Some philosophical implications of behaviorism." (1927). Electronic Theses and Dissertations. Paper 1456.

https://doi.org/10.18297/etd/1456

This Master's Thesis is brought to you for free and open access by ThinkIR: The University of Louisville's Institutional Repository. It has been accepted for inclusion in Electronic Theses and Dissertations by an authorized administrator of ThinkIR: The University of Louisville's Institutional Repository. This title appears here courtesy of the author, who has retained all other copyrights. For more information, please contact thinkir@louisville.edu. 
SOME PHILOSOPHICAI IMPLICATIONS OF BEHAVIORISM 


\title{
UNIVERSITY OF LOUISVIIIE
}

SOME PHILOSOPHICAL IMPLICATIONS OF BHHAVIORISM

\author{
A Dissertation \\ Submitted to the Faculty \\ Of the Graduate School of the College of Iiberal Arts \\ In Partial Fulfillment of the \\ Requirements for the Degree \\ Of Master of Arts
}

Department of Philosophy

By

Harold Wayland Tribble

1927 
To

Nelle Louise Tribble,

loyal and sympathetic companion, this thesis is affectionately dedicated. 


\section{PREFACE}

To write a thesis is not an easy task. One is told that he must be original and yet he must speak with the authority that comes only from wide reading. He must give every author credit for the use made of his work and yet he must write in his own style and language. Yet to write a thesis is a delightful task, for one knows that the requirements are ideal and never fully observed, even by those whose theses become books. So this work has been to the writer both a difficult and a delightful task.

I would like to give credit to all upon whom I have drawn for help. I have faithfully sought to give references where authors have been quoted either directly or in summary, but this is not always possible. Sometimes mental notes have been resorted to where card notes were lacking, and authors' names and books have not always been kept with these mental notes. But the books read are listed in the bibliography.

I do want to take this means of expressing my gratitude to Dr. M. A. Caldwell for his painstaking help and never-waning sympathy and friendship. In the class room and in his home he has blended the 
characteristics of true teacher and understanding friend to a degree that is inspiring in retrospect as it has been in the actual present. Other friends and teachers have helped in ways too numerous to mention. I only hope that I may express true appreciation and gratitude by making the best use of their help in further study.

H. W. T. 
TABLE OF CONTENTS.

Chapter I - Introduction - . . . . . - Page

Chapter II - Metaphysical Implications - - - -17

Chapter III - Logical Implications - - - - - 46

Chapter IV - Epistemological Implications - - 76

Chapter V - Ethical Implications - - - - - 96

Chapter VI - Religious Implications - - - - -112

Conclusion _ . . . . . . . . . . - . 127

Bibliography _ . . . . . . . . - - 130 


\section{CHAPTHR I \\ INTRODUCTION}

I. Definition.

1. Extreme position.

2. Moderate position.

3. Distinction between behavior and behaviorism.

II. History.

1. Beginning about 1912 .

2. Early distinguishing features.

3. Period of development.

4. Present status.

III. Types of Behaviorism.

1. Near behaviorism.

2. Methodological behaviorism.

3. Purposive behaviorism.

4. Radical or strict behavi orism.

5. Synthetic behaviorism.

IV. Method.

1. Of the behaviorists.

2. Of this thesis. 


\section{CHAPTHR I}

\section{INTRODUCTION}

Psychology is the middle ground between philosophy and science. Philosophy deals with the interpretation of facts, with a view to determining their ultimate cause. It is the search for knowledge of general principles-elements, powers, causes and laws-as explaining facts and existences. Science is systematized knowledge of facts, laws and proximate causes, gained and verified by exact observation. Science is the effort to show how laws operate, and how certain facts affect other facts. Philosophy seeks to show why laws operate as they do, and to discern what is the first fact. Science deals with the sequence of erents and effects and their immediate causes. Philosophy seeks to go back through a process of reasoning to the first cause, the uncaused cause, and in terms of that to explain all the series of effects, all the consequent facts and factors. Science goes into the laboratory and experiments. Philosophy goes to the reason and theorizes and then seeks proof of those theories through processes of logic. Science is primarily objective in its method. Philosophy is primarily subjective. Science 
takes phenomena and seeks to discern the facts and factors involved. Philosophy takes a basic fact, or typephenomenon and builds a system around it, or it begins with concrete facts and seeks to gain from them a philosophic truth. It may safely be said that philosophy is the parent, science the offspring.

Between these two great fields of knowledge and partaking of both is psychology. Its tendency has been from the philosophical in method and material to the scientific. In that it deals with the mind it is philosophical. Because it is objective it is scientific. When it analyzes the states and phases of consciousness and passes judgment upon the nature and functions of the soul it is philosophical. When it explains the workings of the neural, glandular and muscular systems of the human organism it is scientific. Psychologists in general prefer to call their field a science, and such it is in the main, but as evidence of the fact that it has always been considered philosophical the average college or university curriculum may be noted.

\section{Definition.}

We have been in the habit of defining psychology as the study of the human mind or soul and its operations, powers and functions. But developments of the past fifteen years require that we qualify the defini- 
tion by stating which particular school or type of psychology is meant. The old standard definition no longer suffices. For example, it does not fit behavioristic psychology. From the standpoint of this school the terms of the definition are obsolete, as are the older methods of study. It would be quite difficult to give a definition of psychology that would set forth all the schools that we have today. It probably would be so general that it would be a very poor definition. It will not be attempted here.

But since our concern is with behaviorism it is well enough for us to seek a definition of this particular school of psychology. Here again we are embarrassed with differences. Not all behaviorists are of the same stripe. What may be true of one group may be only partly true of another, and not at all true of still another group. But we shall never be able to eliminate differences among thinkers. Watson says behavioriam is "a natural science that takes the whole field of human adjustments as its own . . . It is different from physiology only in the grouping of its problems, not in fundamentals or in central viewpoint. Physiology is particularly interested in the functioning of parts of the animal-for example, its digestive system, the circulatory system, the nervous system, the excretory systems, the mechanics of neural and muscular 
response. Behaviorism, on the other hand, while it is intensely interested in all of the functioning of these parts, is intrinsically interested in what the whole animal will do from morning to night and from night to morning." 1

To know what the animal will do under certain circumstances or conditions the behaviorist observes his action under present conditions, analyzes that behavior in terms of stimulus and response, and then predicts the behavior of the animal when the stimuli are known. "The behaviorist asks: Why don't we make what we can observe the real field of psychology? Let us limit ourgelves to things that can be observed, and formulate laws concerning only those things. Now what can we observe? Well, we can observe behavior-what the organism does or says. And let me make this fundamental point at once: that saying is doing-that is, behaving. Speaking overtly or to ourselves (thinking) is just as objective a type of behavior as baseball. The rule, or measuring rod, which the behaviorist puts in front of him always: can I describe this bit of behavior I see in terms of 'stimulus and response'? By stimulus we mean any object in the general environment or any change in the tissues themselves due to the physiological condition of the animal . . B By response we mean anything the animal does-such as turning towards 
or away from a light, jumping at a sound, and more highly organized activities such as building a skyscraper, drawing plans; .. writing books, and the like."2

The behariorist scorns such terms as consciousness, mind, soul, instincts, will, emotions, and substitutes 'response'. These responses, or reactions, he groups as 'unlearned behavi or' and 'learned behavior'. All instincts are the results of training or conditioning -belonging to man's learned behavior. ${ }^{3}$ Yet there are some phases of behavior that he calls unlearned behavior, two of which psychologists have been calling instincts, graspoing and the fear response. The human organi sm is a physical machine which is conditioned by the environment in which it grows from birth to the grave. There is no mind, only a brain, muscles and glands; no consciousness, only reactions to stimuli and muscular retention of the impressions of those stimuli; no emotions, only glandular activity; no thinking, only visceral response (subrocal talking) to internal or external stimuli. In short "the doctrine of behavior$1 \mathrm{sm}$ can be surnmed up briefly in two statements: (1) that psychology deals only with what can be observed; (2) that consciousness is a meaningless term." 4 By observation the behaviorist means what can be done by a photographic plate or a spring balance just as well as by a human being. 
Extreme behaviorism not only says that we can get along without the term consciousness, but it goes on to dogmatize and say that there is no consciousness, that what we have been calling consciousness is nothing more nor less than a mechanical response or group of responses of a merely physical organism to physical stimuli. There is, however, a modified behaviorism which claims that psychology can get along without the term consciousness, but they do not say that there is no consciousness. Neither do they say that behavior is merely mechanical response. They allow for an element of purpose and choice which comes very near being conscious activity. We shall have more to say about them a bit later.

It is perhaps worth while to take a few minutes and a little space to point out that what this thesis is concerned with is behaviorism, not merely behavior. All psychologists are agreed that the study of behavior and the effort to control human activity are the objects of this great field of study. Behavior is activity, and it may be conscious, semi-conscious, subconscious, or unconscious. Behaviorism says it is nonconscious.

\section{History.}

Behaviorism is a modern type of psychology. It is the newest of the new psychologies. It began around 
1912 as a bold break of a few men from the traditional method and terminology of psychology. Perhaps these pioneers did not undertake to forecast the results of what they were initiating. Certainly they only sought to establish a new method in psychology. They urged the need "of a category common to the physiologist and the psychologist in terms of which the problems of bodily and mental function might be discussed without arousing metaphysical prejudices." 5 At first it was quite clear that the behaviorists did not arbitrarily rule out the mental, or the conscious. They merely made the claim that they could present a system of psychology without the use of these or kindred terms. Some even thought that behaviorism would act as a supplement to other psychologies. Bauden, in the article quoted above, suggests that "the data derived from the individual's observation require to be checked by the data derived from observation by other individuals here just as they do elsewhere. The scientific standpoint is always the standpoint of the observer, the third person's point of view." 6

Madam Grace A. DeLaguna, in an article on "Bmotion and Perception from the Behaviorist Standpoint" that appeared in the November 1919 number of the Psychological Review, summed up the status of behaviorism at that time in the following brief statement. "At 
present behaviorism is a program rather than an achievement; a method of approach rather than a the ory possessing scientific credentials." Then she delineated the new movement as to its sources. "So far the behavior1st movement has had two distinct, if not wholly independent sources. On the one hand, we find a group of experimental investigators of animal behavior, occupied with such problems as that of determining what mode of response, if any, is called out in a given species by a given physical stimulus; how given types of reaction are excited, and how they are modified. On the other hand, we find a group of philosophical behaviorists, who are chiefly concerned with the metaphysical aspects of the new doctrine and who devote themselves almost exclusively to the task of defining consciousness in terms of behavior. The two groups of thinkers find a common ground in their conviction that the study of mind and the study of behavior are not two things but one, and that the investigation of the so-called phenomena of consciousness can be fruitfully carried on only through the study of behavior."

These two sources, or trends, have come together in the behaviorist of the present time. He is no longer satisfied to term his movement a method or an attitude, but he insists rather dogmatically that his is the only psychology, the acceptance of which must eliminate 
all differing schools of thought. At present the status of behaviorism appears in three aspects. There is, first, the central problem of an unproved hypothesis which portends radical changes not only in psychology, but in many kindred fields as well. The purpose of this thesis is to follow through same of the philosophical implications to their logical conclusions. It is manifestly impossible to deal with all the problems that behaviorism raises. It would be like following a tap root through all of its branches in an almost unending maze. Second, there is a bold challenge from the behaviorists, the extreme proponents particularly, to all who do not accept their doctrines. "Show us," they say to the subjective psychologists, "that you have a possible method, indeed that you have a legitimate subfect matter. Prove to us that philosophy and the social sciences based upon your speculations have any right to further take up the time and thought of developing students." 7

The third aspect is that of the dogmatic claims that certain results are already being attained by behavioristic teachings. For example, Watson sees introspective and functional psychology giving way to behaviorism. Quite naturally he feels that behaviorism will soon be the only psychology known. He sees philosophy being transplanted by the history of science, 
behaviorism completely obliterating philosophy. Ethics, he thinks, is becoming experimental ethics based entirely upon behavioristic methods. He sees social psychology "rapidly becoming a behavioristic study of how groups-family, village, national, church and the like -build up habits (attitudes) in the individual during the formative period and thus maintain control of him throughout life." "Sociology is merging into behavioristic social psychology and into economics." Religion is "being replaced among the educated by experimental ethics." Psycho-analysis is "being replaced slowly by behavioristic studies on the human child where scientific methods are being established for conditioning and unconditioning the child. When such studies are carried to an ideal state, there should be no reason for psychopathic breakdowns or disturbances in the adult." 8

The establishment of these claims is a part of the task ahead of behavioristic psychologists. Not all behaviorists are so bold or dogmatic in making them. Some seem to follow the leading of the extremists with but a partial understanding of the consequences involved. Others, recognizing the trend of the extreme position, are content to hold a sort of middle ground position, not denying the validity of introspective psychology but affirming the greater practical value of behavior- 
Istic psychology.

\section{Types.}

There are several types of behaviorists. McDougal1 ${ }^{9}$ gives three and Sellars 10 gives four. There is a group who grant the exi stence of facts of consciousness and that those facts are capable of treatment, apart from behavior. They accept psycho-physical parallelism with emphasis on the physical. McDougall calls these the near behaviorist. He says that they are separated from what he calls the strict behaviorists by the fact that they neither deny nor totally ignore the facts of conscious activity. "They give the impression that they would much like to do this, but they have not the courage of their desires. They see that to deny the whole realm of introspectively observable facts is too flagrantly absurd and that to ignore them may be a little dangerous. But they are allied to the strict Behaviorism party by their neglect to make use of the introspectively observable facts and by their acceptance of its 'muscle-twitchism'. For them every instance of human conduct or animal behavi or is merely a mechanical reflex response to a sensory stimulus; and they resolutely shut their eyes to all the objective (as well as the subjective) evidences that behavior is a goal-seeking process." 
Another type admits the exi stence of the facts of conscious experience but denies that they are suited to any form of scientific treatment. This is what Sellars calls Methodological behaviorism. It emphasizes animal psychology. A third type McDougall calls purposive behaviorism, which denies the facts of conscious activity but recognizes fully the objectively observable fact that behavior is obviously a goal-seeking process.

There is a fourth type, which Sellars calls radical behaviorism and MaDougall terms strict behaviorism, which refuses to recognize the facts of consciousness and denies the goal-seeking nature of behavior. Their claim is that behavior can be best explained without any reference to purpose. Mind is behavior and nothing else. This is the extreme position. It is the type of behaviorism that Watson at present is championing. Walter S. Hunter ${ }^{11}$ has elaborated a system which he calls anthroponomy, which is just another name for this type of behavi ori sm.

Sellars suggests a final type which he calls synthetic behaviorism. He bases his statement of this position partly on the articles by Lashley on "Behaviori sm and Consciousness" in the Psychological Review in 1923. Here mind represents a level of organic responses and processes centering in the nervous system and finding expression in muscular activities. The 
total response is behavior. Mind and consciousness are worked into the ordinary system of biology. "Ordinary self-consciousness and introspection give data to psychology concerning the nature of mental responses. This is a monistic, evolutionary position."

In seeking to follow through some of the philosophical implications of behaviorism the purpose of this thesis will be to try to keep in mind the main doctrines of all these groups, with the emphasis naturally falling on the extreme position, strict or radical behaviorism.

IV. Method.

A word as to method may be in order before going into the body of the thesis. The method of behaviorism is objective only. It limits its acquisition of data to one channel, which per force eliminates the benefit of a check which an additional approach would offer. It may be that this is a fundamental defect of the whole system. However, if introspective psychology can be proved to be false there will remain no alterna tive but the single-track objective method. In the meantime it seems evident that the data of behaviorism are dependent upon a certain subjective element, whether ignored or recognized. The behaviorist who observes the behavior of another person under experiment is himself reacting to stimuli (the stimuli and the responses 
of the other one become the stimuli to the observer) and somehow (subjectively?) is interpreting those stimull and devising laws on the basis of his interpretations. It is difficult to see how it is throughout a merely objective method after all. But this will be discussed in a later connection.

The method adopted here is neither objective nor subjective as such, but perhaps both. It is not to be a laboratory study using experiments, but a logical and philosophical study using the data of the behaviorists. The desire of the writer is to eliminate prejudice as far as possible. The effort will be to show what follows if the claims of behaviorism are true, following these claims out to their logical conclusions. These conclusions may have something to do with the validity of the claims. But the claims are to be tested logically. The central and determining principle here is that any theory to gain scientific support must, in its methods and conclusions, accord with the fundamental and generally establi shed principles of science. 
REFERENCES, CHAPTER I

1. J. B. Watson, "Behaviorism," p. 11.

2. Ibid., F. $6 \mathrm{f}$.

3. Idem, "Psychologies of $1925, "$ p. 1.

4. C. K. Ogden, "The Meaning of Psychology," p. 162.

5. H. H. Bauden, "Presuppositions of a Behaviorist

Psychology," Psychological Review, 1918, p. 175.

6. Ibid., p. 181 .

7. J. B. Watson, "Behaviorism," p. 16.

8. Ibid., p. $17 \mathrm{f}$.

9. William McDougall, "Men or Rabots," in Psychologies of 1925, p. $278 \mathrm{j}$.

10. R. W. Sellars, "The Principles and Problems of Philosophy," pp. 314-317.

11. Walter S. Hunter, "Psychology and Anthroponomy," in Psychologies of 1925. 
CHAPTER II

MET APHYSICAI IMPLIC ATIONS

I. Dualism.

1. Twofold meaning.

2. Conclusion from behaviorism.

II. Pluralism.

1. Two types.

2. Pluralistic Idealism.

3. Effect of behaviorism on pluralism.

III. Monism.

1. Idealism.

(1) Definition. Many types.

(2) Behaviorism and mind.

(3) Personalism.

2. Materialism.

(1) Positivism and mechanism.

(2) Behaviorism's type phenomenon.

(3) Energetics and Critical Naturali m.

(4) Mechanistic Evolution.

Conclusion. 
CHAPTER II

MET APHYSICAL IMPLIC ATIONS

The relation between philosophy and psychology has already been suggested. It is an intimate relation, so much so that any radical change in one's acceptance of psychology calls for a corollary change in his system of philosophy. Indeed philosophy is the field of thought that makes use of all other fields of thought. It is "an attempt to gain unity in our thinking." It is, according to Herbert spencer, completely unified knowledge, whereas science is partially unified knowledge. It seeks to bring all the sciences into a unified system. It is an attempt to understand the world and life. It seeks to correlate and combine the results of all the sciences into a world view that will satisfactorily answer the questionings of the human mind as to the use, meaning, purpose and value of life. 1 According to Dr. Hibben, 2 "the problems of philosophy are, in fact, the problems of life, the burden and mystery of existence, the origin and destiny of man, the relations which he sustains to the world of which he is a part, and to the unseen universe which lies round about him." 
Any theory of the mind affects the theory of iffe that the mind holds. Herein ari ses the relation between behavioristic psychology and metaphysics. A more detailed discussion of the behaviorist's view of the mind will be reserved for a later place in this chapter. Here it is enough to point out that his theory of the mind in general is that it is a system of reactions to extermal and internal stimuli. Metaphysics, or ontology, is a branch of philosophy that deals with ultimate reality. There has always been considerable difference of opinion as to the function and character of this phase of philosophy. "Before Kant's time there was a very general tendency to build up theories of the nature of things on the basis of a priori reasoning. Certain metaphysical principles were assumed to be necessary, and the acceptance of these principles led to the deduction of various propositions which were held true of reality as it is in itself, i.e., of reality as it exists without relation to the condition of our experience. This method of procedure is called dogmatism, and the metaphysics thus developed is dogmatic or rationalistic metaphysics." This may be dualistic, as exemplified by Descartes, or monistic, as seen in the system of Leibnitz and Hobbes.

If we could conceive of a negative dogmatic metaphysics that would probably be the type that extreme be- 
haviorism would offer. It moves upon the a priori assumption that there is no consciousness, or mind, or soul, and builds a dogmatic system around this negation. The denial of consciousness is not a conclusion that the behaviorist reaches after a series of experiments, but it is his assumption from which he deduces all the doctrines of his system. His experiments merely serve to support those conclusions. That is a priori reasoning. One needs only to glance through a behaviorist's book to see that it is a dogmatic system.

There are philosophers who hold to a type of metaphysics called empiricism. They derive their knowledge of reality from experience and not from a priori principles. The experience that behaviorigm knows is expressed in terms of stimuli and response, and these are in terms of the general premise, or the assumption referred to above. Still another group holds that, while there is an ultimate reality, it cannot be reached by human faculties. These faculties do not present us with the real as it is in itself, but with the results of their elaboration. Behaviori am denies that we have any faculties, save the muscles and glands of the physical organi sm which respond in a certain manner under certain conditions.

If the assumptions of behaviorism are true then what is ultimate reality? Will the conclusions of this 
school of psychology have anything to do with the conclusions of philosophy as to reality? There are three general philosophical theories of reality: monism, dual$1 \mathrm{sm}$, and pluralism. These theories represent the desire of the human mind for unity in plurality, to find the one in the many. For our purpose here it is well enough to consider these theories in the following order: dualism, pluralism, and monism.

\section{Dualism.}

The word dualism is somewhat ambiguous, being used in philosophy in two senses. It is sometimes used to designate the belief in a good and a bad principle which lie at the root of all things. This particular kind of dualism we may consider later in connection with the implications of behavi orism that bear upon ethics. The other sense in which the word is used is the theory that the universe as a whole can only be explained with two fundamentally different kinds of constituent elements. In ancient philosophy these two elements were matter and form, while in modern times they are mind and matter. Descartes distinguished between thinking substance (mind) and extended substance (matter). The difficulty which this view inevitably raises is to explain how mind and matter interact as they apparently 
do in experience. One of the earliest attempts to solve this difficulty resulted in the denial of interaction and the claim of concomitance of variations, under divine control. "This simply pushed the difficulty a step farther back. If mind cannot act upon matter, then God, concei ved as mind, cannot act upon matter; but conceived as other than mind, cannot act upon mind." 4 A possible modern solution of the difficulty is parallelism, which holds the concomitance of brain processes and mental processes, but denies that there is any relation of cause and effect between the two.

But how does extreme behavioristic psychology handle this difficulty? It is quite evident that for this kind of behaviorism the difficulty does not exist. There is no relation between mind and matter, for there is no mind apart from matter. What we have been calling mind is merely the type of reaction of the organism to the stimulus which, or the results of which, we have observed. This reaction may be muscular, visceral or glandular, but in any case it is a part of the physical organi sm, and not a mind or consciousness that is apart from and yet within the organi an. And so the radical behavioristic psychologist cannot hold to philosophical dualism. The two are irreconcilable. 
II. Pluralism.

Another philosophical theory of reality is pluralism. This is the view that reality cannot be reduced either to one or two ultimate forms of being. Reality is many. This theory runs all the way from kmpedocles, about 450 B. C. - who held that the four ultimate elements of reality are earth, air, fire, and water-down to the present day. Pluralism today is found in two general forms: that of William James, which was the result of his radical empiricism, and the philosophy of the New Realism. The former emphasized the perceptual flux, with such realities as beginnings, ends, indeterminations, evil, crises, catastrophes and escapes, a real God and a real moral $11 \mathrm{fe} .^{5}$ The latter emphasizes the world of reason, thought and values. "Physical and mental things, events and processes are real in this realistic pluralistic system, but so also are principles of reason, logical principles, internal and extemal relations, numbers, space, time, series, and such ideal entities as justice and beauty. These latter non-physical and non-mental entities we may, if we choose, call subsistents, if we wish to limit the term existent things to such as are conditioned by space and time." 6

Behaviorism has no place for subsistents. It neither provides nor implies any way of knowing objects 
independently of space and time. The reactions of the physical organism are only determined by physical stimuli. The claim of the behaviorist that given the stimulus he can predict the response, or given the response he can describe the stimulus, precludes the possibility of holding either of these types of pluralism. Since all human activity is physical response the organism has no capacity for receiving any other than a physical stimulus. Thus even man's thinking (what the behaviorist calls sub-vocal talking) is concerned only with physical objects. The moral life, the conception of God, principles of reason, justice, beauty and such like are not realities but phases of the mechanical adjustments of the organi sm.

There is also a pluralistic Idealism which should be given a place in this grouping. It is perhaps best set forth in the extreme Idealism of Berkeley. Reality, he said, consists of minds, spirits and souls, plus their ideas. God, the infinite Spirit exists, and a rea.lm of finite spirits, but the objects we call material are merely objects of experience. This is pluralistic in the sense that it considers each spirit as having its own world in its own ideas. Leibnitz contended that the onfects we see about us and that we study in science have real existence independent of the mind that perceives them; but that when we come to examine into their real 
nature we find that in their inner being they are mental or spiritual. He developed his system along the lines of the old atomic theory, holding that all objects of sense are made up of certain ultimate units, which he called Monads. Physical bodies are comosed of Monads over which the soul is the governing Monad. These, and all other types of Idealism, may be included in the discussion given below in relation to the effect of the conclusions of radical behaviorism upon Idealistic philosophies.

With these types of pluralism ruled out by behaviorism there are only two alternatives left. Either there may be a pluralism of only material realities, or behaviorism leads to some form of monism. A pluralism of only material realities is not a pluralism at all, but one substance in many forms and manifestations.

\section{Monism.}

The third general theory of reality is Monism. This view also takes two forms, Idealism and Material1 sm. Ideali mm puts the emphasis upon mind, as in some way prior to matter. It holds that mind is real and that matter is only an appearance. There are several types of Idealism, running from plato down to the present day. Plato's Idealism was not extreme in the sense that there is nothing in the universe but mind. 
He taught rather that the significant things of the universe, the real things, are Ideas, and by Ideas he did not mean merely mental states. "He meant real objective things or 'forms' which are not material."7 They are patterns or standards for the things of sense. These patterns, such as beauty, truth, justice, and goodness are the cosmic realities, while what we call matter he termed non-beine, not that it does not exist, but it does not have significance. Panpsychism is another type of ideali $\mathrm{mm}$. According to this view, as the word indicates, all reality is psychic in nature. This solves the mind-body problem on the basis of correlation between mind and brain. The mind is the sole reality, the body is its outer appearance.

Voluntaristic Idealism reduces the universe to absolute will. The physical world is but an expression of will. Kant made the distinction between the noumenal and phenomenal realms. The phenomenal world is the objective world of our experience. The noumenal is the realm of reality back of phenomena. Kant called it the Ding an Sich, or thing-in-itself. Finally, there is Absolute Idealism. Fichte taught that reality is swallowed up in the ego, the Absolute Ego, the supreme reality. Hegel said that reality is reason. The world is a great thought process. "What we call nature is thought externalized; it is the Absolute Reason reveal- 
ing itself in outward form. But nature is not its final goal. Returning, it expresses itself more fully in husman self-consciousness and in the end finds its complete realization in art, religion, and philosophy. " 8

Now, what of behavioriam and these types of Idealism? In the first place let us examine behaviorism a bit more thoroughly than we have done with reference to the place it gives mind. Watson regards mind as a passing and useless concept. In the place of the 'concept mind he would have a description of the way the whole body behaves. To show the needlessness of the term 'mind' he describes a fanciful picture of a dog trained to spurn fresh steak and to eat decayed fish. By use of electric shocks he was trained to fear and avoid female dogs. Through other processes he was made over into a whining, growling, emaciated specimen of canine flesh and bones. Then, (without referring to the dog's mind) he trains him to be friendly with other dogs and with man, to eat fresh meat and to sleep naturally, until finally Wation sees his imaginary dog take the blue ribbon in a show over the best bred and pedigreed and most intelligent dogs of the land. Thus would Watson meet the needs of the mentally sick man. We are not concerned here with the question of mental diseases, whether there are any such and how to cure them (it is in this connection that Watson introduces the above il- 
lustration), but this indicates the point we are searching for here in our study. He allows no place for mind in his system of psychology. He does not find any evidence of it, and should he stumble across some signs that point to the presence of a mind he could not deal with it without disrupting his whole scheme.

As has already been pointed out there are behavforists and behaviorists and they cannot all be put under the same label. The only way we have of knowing behaviorism is through its proponents. It is evident that some of these are more liberal toward the mind concept than the extremists. For example, Bauden says that mind is behavior of a certain sort. "It is behavior in which certain objects which serve as excitants are undergoing experimental reconstruction into stimuli adequate to the incipient response. It is behavior in which certain attitudes are undergoing reorganization into adequate attentional discrimination of the response." 9 He goes further in this strain to define psychology as "the science of the behavior of organisms in so far as they exhibit mentality. Behavior-not all behavior, but behavior in so far as it presents the character of the mental as distinguished from the chemical, the physical, the vital. Mentality-behavior in its aspect as inducing fresh forms of itself."10

Wieman says that "mind or mentality means a certain 
mode of doing things on the part of an organism. "ll He gives an illustration from Holt's "The Freudian Wish" of a man who is fond of mushrooms. He finds some but is afraid to eat them lest he should get some of the poisonous species. He is in a conflict of emotions. The basis of adjustment is the ability to distinguish between the good and the poisonous mushrooms. "Mentality," he then concludes, "is the process by which various stimulated tendencies of the organism are adjusted to the execution of a series of movements resulting in adaptation to the environment. Its mode of operation is the organization of diffusive tendencies into a definite system under the control of some dominant propensity having an instinctive basis. This propensity consists either of an innate series of reflexes or of some system of tendencies which has been organized in the past experience of the individual and which persists as an established physiological motor set."12 This is not the language of a radical or strict behavlorist, for there is too much importance attached to attention and instinct. Watson would brush this aside and go back to the question of stimulus and response, with the response conditioned only by previous stimuli. Mind and consciousness are kindred terms. By many they are used synonymously. To say the least, they are two concepts that are hard to define. The strict be- 
haviorists make a great deal of this difficulty, arguing that it is due to a fundamental error, namely, an effort to define something that doesn't exist. Whatever the definition may be it is surely agreed that one's psychological interpretation of consciousness determines largely his philosophical interpretation of reality. That is our purpose in seeking some sort of definition here. The Relational Theory of consciousness, as first formulated by Woodbridge, holds that "Consciousness is the result of the interaction between the organi am and its surroundings." 13 Colvin and Bagley describe consciousness in the following terms. "It is therefore reasonable to assume that consciougness puts in an appearance when it is required to ald behavior. The service that consciousness renders is to adjust the organism better to its surroundings. When there is perfect adjustment there is no need of consciousness; when, however, the organism is not so adjusted, then consciousness is necessary in securing a better adjustment." 14 Such a description 1s far from 1dentifying consciousness and physical behavior. The position represented by Eliott P. Frost is an advance step in the behavioristic tendency. He says, "energy is stored in some modified fashion by past experience; it is put in action by the stimulus now affecting the organism; its result is to modify the machinery of behavior in terms 
of that past experience. This is what and this is all that psychology can mean by conscious processes." 15 This leads logically to the position represented by Lashley. "The concept of consciousness," he says, "is then, that of a complex integration and succession of bodily activities which are closely related to or involve the verbal and gestural mechanisms and hence most frequently come to social expression. The elements of content are the processes of reaction to stimulation and do not differ in essential mechanism from the spinal reflex of the decapitated animal to the most complex adaptive activity of man." 16

There we have the place that radical behaviorigm provides for mind or consciousness. They are but vague terms that other psychologists use to designate what the behaviorist thinks of as the action of the whole organism. And so it is quite plain that he would not embrace Platonic Idealism, for he reacts only to material objects (what Flato called the non-being), and he would never get the significance or forms or ideas of those objects. In like manner the subjective Idealism of Berkeley means nothing to the behaviorist, for he does not belleve in the existence of minds or spirits or souls. So also with Leibnitz's Monadology and with Panpsychism, and Voluntaristic, Kantian, and Absolute Idealism. When behaviorism drops all reference to the 
mind and reduces what we have called mental aetivity to physical behavior it also closes all doors that lead to philosophic Idealism.

There is, however, a modern type of philosophy which is not monistic but is very close kin to Idealism. It is Personalism. It holds that ultimate reality is personality. Prof. Ralph Tyler Flewelling, in his book "Creative Personality," points out that reality must abide and yet undergo change. Only personality meets this test. Material objects have significance only as they come in contact with persons. They exist, but not for meaning apart from persons. Space has no meaning save as persons relate objects. Time is meaningless save as persons relate events in past, present and future time. Motion is a fallacy unless it is gauged by some person. Ideas are but the thoughts of persons.

Now, the behaviorist defines personality as "the sum of activities that can be discovered by actual observation of behavior over a long enough time to give reliable information. In other words, personality is but the end product of our habit systems."17 By habit he means repetition of conditioned response until it occurs readily upon a very slight stimulus. All such conditioned responses constitute what we call personality. There is no will in personality, though one 
type of moderate behaviorists admits a goal-seeking element in human activity. Yet it is difficult to see how there can be any purpose or goal-seeking in behavior without some element of what we call conscious activity. This definition of personality also leaves out emotions. Watson defines emotion as "an hereditary 'pattern-reaction' involving profound changes of the bodily mechanism as a whole, but particularly of the visceral and glandular systems." 18 If such a definition means anything, it is that emotion has nothing whatsoever to do with what we have been calling conscious activity, but that it is another name for physical response. And so personality is not a factor but a result of physical stimuli. The only thing necessary to change personality is to have the stimuli strong enough. Thus personality does not abide, but changes with conditions. Then there is no supreme personality as ultimate reality, but for every personality there must be greater stimuli to evoke the responses that make the personality.

\section{Materialism.}

The other type of monism is materiali $\mathrm{sm}$. It $1 \mathrm{~s}$ the view that the world is best explained as a redistribution of matter, that there is nothing in the world but matter, that mind is a form or a function of matter. From Democritus on Materialism has frequently taken the 
form of Atomism, indeed the two terms have at times been used interchangeably. Here all matter is thought of as consisting of an almost infinite number of particles, called atoms, which whirl about in space, thus giving not one basal concept as monism requires, but three-atoms, space and motion.

These concepts have led to the modern type of materialism known as Naturalism or positivism. It places more emphasis upon the mechanical character of the world process and less upon the substantial ground of the world. This is the emphasis of the physical sciences upon philosophy. Indeed positivism limits philosophy to the results of the natural sciences. This is to be expected when all other methods and subject matter than those of physical science are discarded. The only philosophy that can fit into such restrictions is mechaniam, and this is about the only type of materialIsm to be found in the present age. Perhaps it should be said that mechanistic philosophy is not so popular among philosophers as it is among scientists who have ventured into the field of philosophy.

Every system of philosophy must have some type phenomenon or basic assumption upon which it builds and from which are ultimately drawn all its conclusions. If an extreme behaviorist should have a philosophy it would have to be in terms of the stimulus-response formu- 
la. That would be his type phenomenon. He claims that given the stimulus he can predict the response, or given the response he cen describe the stimulus. He also claims that all responses of the human organism are solely physical adjustments to those stimuli. Over these responses there is no human intelligence ruling. Only as we are conditioned by certain stimuli can we rise to greater and nobler responses. The implication in the se claims is that there is no spirit nature in man. It is even more than an implication, for the radical behaviorist brushes aside the mind concept and consciousness. For him the organi am is made up of the sense organs, the reacting organs, consisting of the striped muscles, the unstriped muscular system of the viscera and the glands; and the nervous system, which consists of the brain, spinal cord and the peripheral nerves which run from sense organs into brain and spinal cord and thence to the muscles and glands. There is no place in all this system for any semblance of the spirit nature of man.

Extreme behaviorism goes yet farther and eliminates the spirit outside man. Since man is capacitated only to respond physically it is inconceivable that a spiritual stimulus would call forth any response at all. Hence man cannot know anything about a spiritual world or a spiritual being if there is any such. The behav- 
iorist claims that man is equipped only with the learned and unlearned response system of the organism, and can only observe that which comes to him in the form of stimul1. Thus his philosophy would have to be materialistic, and, since he places more emphasis upon the process of conditioning and response it must be mechanist1c. His laws are the laws of the conditions and responses, and so if he should observe that certain laws operate in the universe he would conclude that they were the resultants of certain conditions, which in turn resulted from certain other conditions, and so on back in an infinite regress.

When we say that radical behaviorism is materialistic and mechanistic we may expect a protest from some of 1ts adherents. Lashley answers, "perhaps it is such, to the extent that modern physics and physiology are materialistic, but the word materialism implies a metaphysical theory of reality, whereas these sciences are, at least in their systematic treatment, altogether phenomenological. Psychophysical dualism and epiphenomenalism do imply theories of the ultimate nature of mind and matter, but behaviorism claims to avoid this and to attempt nothing more than a logical and a mathematical description of experience such as is presented. by the physical sciences. To stigmatize this as materiali $\mathrm{mm}$ is to appeal against behaviori $\mathrm{sm}$ to the prejudices 
aroused by a crude metaphysic which is nowhere implied in its doctrines."19 We reply in his own words. "The acceptance of a physical world seems to me to involve as a corollary a behavioristic psychology." 20 That is a rather clear and positive implication that the behaviorist has a theory concerning ultimate reality. If behaviorism is the logical corollary of the acceptance of a physical world, then behaviori $\mathrm{sm}$ must be built upon the assumption that there is nothing but a physical world.

The behaviorist may suggest that the physical world is not necessarily matter, that it may be energy. Could a behaviorist hold a philosophy of energetics and deny materialiam? 0stwald propounded the theory that "the various properties of matter are special forms of energy (kinetic, thermal, chemical, magnetic, electric, etc.), which cannot be reduced to one another. Psychic energy is another form of energy; it is unconscious or conscious nervous energy. Interaction is explained as the transition from unconscious to conscious energy or the reverse." 21 Thus it seems that energy is an attribute by virtue of which matter can effect changes in other matter. Philosophy is primarily interested in the qualitative, rather than the quantitative, attribute of reality. Perhaps that explains the fact that the theory of energetics has been left largely to the 
field of the exact sciences, principally physics and chemistry. At any rate the behaviorist would have no place in his philosophy for the theory of energetics, for everything that man knows is reduced to a part of the physical (muscular) organism. Energy, then, for the behaviorist is a secondary consideration, the conditioning of the muscular organization being primary. This primary concern must be the type-phenomenon by which we characterize a philosophy.

In the same manner would critical naturalism be automatically set aside by strict behaviorism. This form of naturalism rejects the qualitative constancy of substance and holds that it can only be quantitative. "In order that such a version of science shall yield a naturalistic philosophy, it is necessary to show that nature so construed coineides with knowable reality. This conclusion may be arrived at in one or both of two ways. It may be argued that the ultimate qualitative terms of experience are somehow physical, or at any rate such as to permit of being explained only in terms of physical theories; or it may be argued that physical theories are the only verifiable, and so the only valid, theories. In other words, the priority of physical science may be argued from the nature of fact or from the nature of method. The former of these motives is represented by sensationalism,' and the latter by 'ex- 
perimentalism." 22 It would seem, from this brief presentation, that critical naturalism would be the philosophical outcome of behaviorism. But the behaviorist can only know nature as it becomes a part of his muscular organism through his responses to stimuli. To talk about energy in matter and prior to matter would be too speculative and metaphysical for the behaviorist. He is satisfied in dealing with muscles and glands, as one moulds clay, and brushes aside every other explanation of human activity. If there is nothing else to human behavi or but manipulation of muscles and glands (without mind, spirit, or nervous energy), how can we arrive at any different theory of the nature that is external to us?

Watson in his system of behaviorism is not so modest as Lashley. In his definition he claims the whole field of human activity. That certainly implies a theory concerning man's knowledge of reality. He goes further and repudiates philosophy. Now it is commonly accepted that the most presumptuous system of philosophy is that which denies that we can know anything about reality. The implication is that one must know a great deal about reality to be able so to limit it in man's thinking. Behaviorism claims to be able to analyze all of man's relations and to predict the responses of the human organism, as you would predict the 
action of your automobile when you feed it gas and oil and apply electricity. The basis of that claim is a mechanistic philosophy. McDougall says that most behaviorists were mechanists first and behaviorists secondarily only. 23 "Behaviorism is the consequence," he says, "of carrying the mechanizing tendency in psychology to its logical conclusion, and indeed to a point some distance beyond its logical conclusion." 24

As a further support of this position the behaviorist has called in a theory of evolution that is both materialistic and mechanistic. "Through the process of evolution," says Watson, "human beings have put on sense organs-specialized areas where special types of stimuli are nost effective-such as the eye, the ear, the nose, the tongue, the skin and semi-circular canals. To these must be added the whole muscular system, both the striped muscles and the unstriped muscles. The muscles are thus not only organs of response-they are sense organs as well."25 This sounds very much as if watson is holding to the theory of evolution that is most convenient for his scheme. In the light of his doctrine of behaviorism it would seem that his theory is a mixture of Lamarck's inheritance of acquired characters and Darwin's natural selection. He has nothing to say about causes and so his view appears to be Darwinian. He speaks of inheritance of physical 
characteristics, though he does not show that acquired physical characteristics are inherited. He speaks of the child of a musician who gives promise of becoming a great pianist. It is not the child's talent for music that he has inherited from his father, but his long tapering fingers that make it easy for him to handle the key board. The fact that he has such fingers leads the fond parent to give him special attention and the very best training, until he becomes a greater musician than his father. Now the behaviorist is not interested primarily in the biological or philosophical question of where the father got his long tapering fingers. Our inference would be that he got them from his father, and he from his father, and so on back until we would have to come to some stimulus that would call forth a reaction that would necessitate the elongation of the ingers.

But Watson gives us another illustration of a father who is ambitious that his child shall become a great musician, but the child has short stubby fingers. Not to be outdone by such a difficulty the father has a piano built to fit the boy's hands. With such a perfect physical fit the boy is ready to thrill the world with his musical genius. This is another of Watson's fanciful pictures, but it serves to indicate where his thinking would lead us in philosophy. If it is merely 
a matter of the length of the fingers and long musical fingers are acquired through a process of evolution, why wouldn't the lad develop long fingers through a process of reaching for the key board of a piano that is built for long fingers? But if the piano must be built to fit the size of the boy's fingers surely physical characters cannot be acquired, and so Lamarck's theory of the inheritance of acquired physical characters must be rejected. The only other theory of evolution that harmonizes with the above statement of Watson is Darwinism. Any philosophy that is based upon that view must be mechanistic.

What then is the type of philosophy to which behaviorism leads? We have eliminated pluralism, Idealism and Personalism because the behaviorist eliminates mind from his thinking. As stated above, the strict behaviorist disclaims having any philosophy at all, but we need not tarry with that, for the mere fact that he denies having a philosophy and rearranges the fields of knowledge to suit his scherne is prima facie proof that he has a rather distinct form of philosophy. In the light of the above discussion I believe we can see that it is a monistic and mechanistic materialism. A more docmatic or closed system of philosophy is difficult to conceive. But it is characteristic of behaviorism to be dogmatic, and its tendency is toward a closed system. 
It leaves the universe a hopeless problem, worse than Haeckel's riddle. It leaves the problem of man unsolved as to origins and future. Indeed it solves the problem of man by denying that there is a problem. 
REFBRIENCES, CHAPTHR II

1. G. T. W. Patrick, "Introduction to Philosophy," chapter I.

2. John Grier Hibben, "The Problems of Philosophy," p. 3. (quoted by Patrick, p. 9).

3. The New International Encyclopedia, vol. 15, p. 489.

4. 오. eit., vol. 17, p. 346.

5. William James, "The Will to Believe," p. IX.

6. G. T. W. Patrick, op. cit., D. 259.

7. Ibid., p. 240.

8. Ibid., p. 248.

9. H. H. Bawden, "The Presuppositions of Behavi orist Psychology, " Psych. Rev. 1918, p. 189.

10. Ibid., p. 190.

11. H. M. Wi Iman, "The Nature of Mentality," Psych. Rev., May 1919, p. 230.

12. Ibid., p. 245 f.

13. H. H. Bawden, op. cit., p. 181.

14. Colvin \& Bagley, "Human Behavior," p. $16 \mathrm{f}$.

15. Bliot P. Frost, "Cannot Psychology Dispense with

Conscience?" Psych. Rev, 1914, p. 252.

16. K. S. Lashley, "Behavi orism and Consciousness," Psych. Rev., 1923, p. 341. 
17. J. B. Watson, "Behaviorism," p. 220.

18. Idem, "Psychology from the Standpoint of a Behaviorist, " p. 215 .

19. K. S. Lashley, op. cit., p. 241.

20. Ibid., g. 343 f.

21. Frank Thilly, "A History of Philosophy," p. 493.

22. R. B. Perry, "Present Philosophical Tendencies," p. 76.

23. William McDougal1, "Purposive or Mechanical Paychology," Prychological Review, 1923, 2. 274.

24. Ibid., p. 278.

25. J. B. Watson, "Behavi ori sm," p. 12. 


\section{CHAPTER III \\ LOGICAL IMPLICATIONS}

I. As to thinking and thought.

1. General definition.

2. Behaviorist's definition.

3. Reasoning.

(1) The behaviorist's definition of 'solution.'

(2) Memory and imagination.

4. Pexcepts and concepts.

II. Deduction.

1. Definition-Twofold effect of behaviorism on logical definition.

2. Assumptions. Fallacies involved.

III. Induction.

1. Definition.

2. Can we gain certainty through induction?

3. False induction.

Conclusion. 
CHAPTER III

IOGICAL IMPLICATIONS

Logic is the science of thought. It is the field of organized knowledge that revolves about the principles and conditions of correct thinking. It is thus "reflective thinking about thought." It is a branch of philosophy that pervades all fields of thought. It is the science which controls all the sciences. Consciously or unconsciously, intentionally or unintentionally, we use logic every day in every form of study. Its place in psychology and philosophy is central and of exceeding importance. Since psychology deals with behavior, mind and consciousness it is patent that it includes thinking, the realm of $\log 1 \mathrm{c}$. And since behaviori $\mathrm{mm}$ is concerned with the behavior of the entire human organism it is evident that it includes thinking. So there is much that psychology and logic have in common, and there is naturally some overlapping. Yet there is a marked distinction between the two fields, chiefly in method and aim. Psychology uses the method of observation and experimentation, and seeks to give a description and explanation of its data. To this extent it is like biology and chemistry. Yet it must also reflect upon the results of its 
observations and experiments. Logic is rather analytic in examining thought, wherever found, to determine the form and principles of 'valid thinking.' Psychology studies the brain and neural processes involved in thinking, while logic studies the principles of thinking with a view to improving it. These principles are established and recognized as standards of thinking and all of us desire to measure up to them. Logic does not deal with the capacities of man for thought save to train and sharpen them.

Logic has ever been regarded as one of the fields of philosophy along with ethics, aesthetics, metaphysics and the theory of knowledge. Its importance has grown and its value has become felt to such an extent that it has assumed almost a determinative place in philosophy. Certain forms of logic lead to certain types of philosophy. Indeed it has become a field of science to itself with its own subject matter. "It is interested in the laws of thought, the nature of proof, the rules of evidence; it desires to see how knowledge is built up and how the parts of knowledge depend upon one another." I Its relation to psychology and philosophy is so intimate that it is worth while and well within the province of this thesis to ask what effect the conclusions of behaviorigm will have upon the principles of logic. 
I. Thought.

Thinking has been defined as problem solving. Dewey ${ }^{2}$ sees four different ways in which the terms thought and thinking are employed. There is first the broad use, designating everything that comes to mind. To think of a thing is just to be conscious of it in any way. Then there is a restricted use in which whatever is presented directly through the senses is excluded. Then there is a third meaning that is limited to beliefs that rest upon some kind of evidence. In cases where the ground, or basis, for beliefs is deliberately sought and its adequacy examined the fourth type, or reflective thought, is found. In other words, thought is relating ideas in the effort to solve the problems in such a way as to lead to the discovery and proof of the solution. Such, in general, is the definition of thought that logic offers.

The behaviorist says that thinking is sub-vocal talking. He "advances the view that what psychologists have hitherto called thought is in short nothing but talking to ourselves. The evidence for this view is admittedly largely theoretical but it is the one theory so far advanced which explains thought in terms of natural science. I wish here expressly to affirm that in developing this view I have never believed that the laryngeal movements as such played the predominating role in 
thought. . We have all had the proofs before us time and again that the larynx can be removed without completely destroying a person's ability to think. Removal of the larynx does destroy articulate speech but it does not destroy whispered speech. Whi spered speech (without articulation) depends upon muscular movements of the cheek, tongue, throat and chest-organization which, to be sure, has been built up with the use of the larynx, but which remains ready to function after the larynx has been removed. My theory does hold that the muscular habits learned in overt speech are responsible for implicit or internal speech (thought)... Again, after our overt speech habits are formed, we are constantly talking to ourselves (thought). New combinations occur, new complexities arise, new substitutions take place-for example, where the shrug of the shoulders or the movement of any other bodily part becomes substituted for a word. Soon any, and every bodily response may become a word substitute." 3

Watson sees support of his theory in the child's behavior. 4 He talks incessantly when alone. Soon society restrains his talking aloud, and the overt speech dies down to whispered speech, and finally to speech behind closed lips (thought). Thinking, then, according to the strict behaviorist, is the subvocal use of words which have already been habitized. These words 
are the substitutes for the objects that have stimulated us, and so we are enabled to carry those objects around with us. We possess these objects (words) as we respond to the stimuli that they constitute for us. "Verbal, manual and laryngeal activities become organized together as parts of the total habit system we form around each object and situation in the world we. live in. " 5 And so it is evident that for the strict behaviorist thinking is a matter of the activity of the physical organism. It is no more, no less. The responses of the organism to the stimuli are the effect of the stimuli upon the striped or skeletal muscular system, the unstriped muscular system or the viscera, and the glandular system. All these systems are active when the organi zm responds to stimuli in what we call talking. When a word is substituted for an object it makes an impression upon the muscular or glandular system and that impression is intensified by repetition. For every object we have a word substitute and so we carry the world around with us as an actual part of our bodily organization. The organd can mantpulate the se words in the throat or larynx, but it is physical activity and not mental. This manipulation is thinking for the extreme behaviorist. If we ask him who does the manipulating he answers "the organism." If we ask him why this manipulating is done he answers that it is because certain stimuli evoke that 
type of response. If we ask him if there is any design or purpose in it his logical answer would be no. It is somewhat like spinning a top. There is a stimulus that acts as the string to set the top in motion and it continues in that same kind of motion until the effect of the stimulus dies down.

If the radical behaviorist is right and thinking is no more than such manipulation what is the value of logic? The implication is that logic can only be the study of the manipulation of these muscles to lead to better thinking. But there would be no principles to guide, for a principle is not an object and so would have no word substitute and would leave no muscular impression. Logic then would be a science of physical mechanics. Thinking would be problem solving of the trial and error type. There is, however, a serious gap right here that either behaviori sm or behavioristic logic would have to fill. It must be proved, and it hasn't been done yet, that thought is identical with muscular action. It is interesting to talk about the muscles that are employed in talking and then to say that thinking is the same thing, but saying so does not prove that they are identical. What about the man who is called on for an exterporaneous speech and as he is talking he is thinking ahead of what he is to say next? But the behaviorist would say that that is only the evi- 
dence of the introspectionist. We will examine the logic of such a position later.

The question that arises here is, what about the words that do not represent objects? Let us take a sentence at random from Watson. "Think what it means in the economy of time and ability to call out cooperation from groups to have word substitutes for objects common to all members." What object does 'think' represent? Has anyone ever seen the muscles of the larynx manipulate the parts of the larynx or the muscles that carry the words of this sentence? If one could observe that manipulation while the organism is thinking would he be able from his observation to tell what the organism is thinking about? Again, what object does 'what' represent? And what about the word 'means'? Is there any meaning other than the object for which the word is substituted? Once more, for what object is 'time' substituted? When that word is brought into use by manipulation what does it signify? And so on with the other words in this sentence, and it is the same w1th many words in the average conversation or paragraph.

The behaviorist may tell us that the words that are not substituted for objects are a part of the organization of the word substitutes which we use in talking about objects. If that be the case then by 
what rule or process do we choose the organization words and use them consistently? It must be rather a chance affair, without the guiding of consciousness. It is difficult to understand how we could receive such words from other persons, since they might not be related to any objects. But that brings us to the question of reasoning.

Lashley sees three classes of thought: (1) the relatively unordered drift of revery; (2) the reproduction of habitized sequences, as in the flow of memorized material; (3) creative thinking, involving a problem set and a solution reached. "The third class presents the supposedly creative work of consciousness. Subjectively, the problem seems to present three phases: determination of sequences, conflict of elements of content, and resolution of the conflict." 6 This third class is what we ordinarily call reasoning. Lashley's definition is a good one. Except for the subtle words 'supposedly' and 'seems' it may well have come from an introspectionist. Indeed he sees that and guards against anything but a behaviorist use of his definition by later making the statement that "the description of a rat opening a problem box is as corplete an account of the process of thinking as can be given from introspective data." "

Again the stimulus-response formula comes into play. 
The behaviorist tells us that so long as there is a stimulus just so long is the problem unsolved and the reasoning continues. When the stimulus ceases the problem is then solved and reasoning ceases, just as the problem of getting food is solved when the nagging stimuli from the stomach have died away. "So with the man's verbal conclusions and judgments. The adjustment is complete-the problem solved for him-as soon as he has made a verbal (or other) response which allays, causes to lie down, intraorganic stimuli impelling him to further verbal activity. "8 But such is not the case at all in logic. When one has found the solution of his problem he finds that one of the greatest problems of reasoning lies just ahead, that is the proof of his solution. We can not answer this criticism by saying that the quest for the proof is the stimulus that is still unsatisfied after the solution has been reached. When we reach the solution of a problem by reasoning we get the relieved, satisfied reaction, but it is usually momentary only. The further question of the proof arises at once, to answer the hypothetical critic. This is not necessarily a part of the intraorganic stimulus, for the organism is often satisfied when the solution is reached. The need for the proof is not felt until someone asks concerning the solution, or unless we are not entirely satisfied. We 
frequently foresee that and acquire the proof before the actual stimulus is received.

But let us look a bit farther at Watson's definition of solution that is reached by reasoning. If the solution is acquired when the intraorganic stimuli die down, and such is an indication that the solution has been reached, then it may be sometimes the key to the problem and sometimes entirely apart from the problem, having no connection with it at all. For example, a neighbor's boy brings an algebra problem to me to solve. He enlists my sympathy and soon I am interested in the problem. I begin to realize that I have forgotten much of the algebra that I once knew, and then there arises in me a desire to solve the problem just to show the boy and myself that I can do it. Just at this point the 'phone rings and my attention is drawn to a golf game. The boy with the problem is put aside with the promise of help later. A few hours later, the game over, my attention returns to the boy. But he tells me that his father has just worked the problem, and has found the solution. That satisfies me, silences the intraorganic stimuli, and at once I proceed to forget the problem in favor of the evening paper. I did not in any sense solve the problem, yet my reaction has satisfied Watson's definition of the solution that is the object of reasoning. It can thus be seen that 
reasoning for the behaviorist is somewhat mechanical and unreliable, determined almost entirely by the condition of the physical organi sm.

The contribution that behaviorism would make to logic on this point would be a very easily attained objective in reasoning. In fact, to lower it to the plane of allaying intraorganic physical stimuli would vitiate all principles and standards of reasoning. When one is disturbed with a great problem why not just eat a big dinner? All of us know that a full stamach calls much of the blood from other parts of the body to aid in the work of digestion. This automatically diminishes the stimuli to thinking. It is difficult to think while the stomach is full. This is at least the natural way of satisfying physical stimuli, and certainly it would be much easier, and often more pleasant, than staying with a difficult problem until it is solved.

There are two psychological phases of thinking and reasoning that we may bring in for a brief examination in relating behavioristic psychology to logic. They are memory and imagination. The behaviorist says that memory is merely a matter of organization. We meet people, get acquainted with them, learn to know them and in this way they become a part of our organization. We are daily being organized by the people we meet, the books we read and the events that happen to us. In 
learning sometimes the organization is manual, sometimes it is verbal, and sometimes it is visceral. Usually it is a combination of all three. "By 'memory,' then, we mean nothing except the fact that when we meet a stimulus again after an absence, we do the old habitual thing that we learned to do when we were in the presence of that stimulus in the first place." 9 Thus the behaviorist contends that after a manual act has been learned and formed into a habit and then put aside for a definite period of disuse, some loss in efficiency occurs, but the loss usually is not total. The amount of loss depends upon the length of the period of disuse, and upon the individual. "So, instead of speaking of memory, the behaviorist speaks of the retention of a given habit in terms of how much skill has been retained and how much has been lost in the period of no practice. We do not need the term 'memory,' shot through as it is with all kinds of philosophical and subjective connotations." 10

In like manner does the behaviorist explain mental imagery on the basis of physical reaction. If a small part of the retina is stimulated and then shaded the person will often behave for a good whlle after as though the retina were still being stimulated. The effect is either a positive after-image or a negative after-image. "The two effects can be made to alternate 
by alternately stimulating the eye with diffused white light and then removing the stimulus. Under suitable conditions these effects may persist for a long time but they gradually diminish both in intensity and saturation. They are capable, however, of being revived to an intense degree many hours after they have disappeared if the eye is adapted to darkness. They may have quite a deal to do with the character of dreams and so-called 'mental imagery,' and may play an important part in hallucinatory experience." 11 He goes on to remind us that the eye is always under stimulation, carried on sometimes by lens adjustment and change in convergence and divergence of the eye-ball; and sometimes by centrifugal neural impulses reaching the eye from the central nervous system. Thus the retina, a delicately susceptible sense organ, is subject to stimulation from within as well as outward stimulation of light. Pathological cases demonstrate this. The retina is probably overactive so far as these internal changes are concerned and the subject appears to be reacting to visual objects to which other persons present do not react.

Extreme pathological cases do not have to be called in. Since the behaviorist has to accept the testimony of the subject in those cases, for the observer cannot see what the subject claims to see and so the behaviorist says it is an apparent reaction, why not take an av- 
erage man's word for what he sees? Here is the case of a man sitting down and recalling a funny incident that happened ten years ago. He says that he can see it all as plainly as if it were happening at that moment. As he visualizes it he breaks out into a hearty laugh. That is as clear a case of imagery as the pathological cases. But the behaviorist does not admit it. If he does it is an admission of mental imagery with slightly different terminology.

With no memory and no imagery, save as they are physically retained and recalled, reasoning is robbed of two of its livest factors. Here is a problem concerning a child. As I look at him I recall certain experiences in my childhood days. I claim to see certain scenes, buildings, trees, children that were common to me in those days but that have long since changed. Then as I look into this youngster's face I imagine him as a grown man in an office managing a business enterprise. That is my testimony of a part of my reasoning process as this boy stands before me. But the behaviorist says, "Pooh, pooh, you are an introspectionist. There is nothing in that for me to observe and therefore there is nothing to it." And so if we follow strict behaviorism out to its logical conclusion we will have nothing left of reasoning processes but a juggling of word substitutes, as stimuli arise, in an imageless, memoryless, 
proofless procession of physical reactions.

The behaviorist's doctrine of word substitutes for objects gives rise to the question of percepts and concepts. A percept is the interpretation we make of a sensory stimulus. When we see a tree the word substitute for that tree that we take away with us is a percept. But we see scores of trees every day and so when we use the word it does not represent any particular tree but trees in general or a type tree. This general type word (or 1dea) is what the logician calls a concept. It is the object of awareness which is not directly connected with the stimulation of the sense organs, and which is under the individual's control so far as having them or not having them is concerned. 12 Now the behaviorist says that a word is a substitute for an object and that it becomes a part of our muscular organization so that we can manipulate it. We can manipulate words with other words, but behaviorism does not take into account any ability of interpreting the stimuli which these words represent. They are built in responses and may be called forth again by other stimuli. Bach word is substituted for an object. When we use the word tree, which tree does it represent? I have seen a number of kinds of trees. Some of them are known for their foliage, some for their blossoms, others for their fruit, others for their value in providing shade, some for their 
sap, and still others for their grain of wood. And so when I use the word tree I may refer to any one or all of these types, or to a general type that includes them and others that I have not yet seen. This is accomplished by classification, but who makes the classes? As we receive these stimuli is there some mechanical device for pigeonholing them? If so we may have percepts and concepts. Can we learn of such an inner process by observation?

II. Deduction.

There are in the main two types of logic, deductive and inductive. Deductive logic accept $\mathrm{s}$ a given general proposition, or assumption, and from it, together with a less general or a particular proposition, draws a conclusion. It is reasoning from general principles to particular applications. Since behaviorism, with one fell sweep, has brushed aside all the general principles and conclusions of psychology and philosophy of prior and contemporaneous times, there are left only two general propositions (bases) from which to deduce particular conclusions. One is the group of definitions that are proposed and the other is the general assumptions which are characteristic of this school of psychology. Let us look at these two classes of deductive thinking as behaviorism affects them.

Logic cannot go far wi thout definition. It is 
basic in all our thinking. We have been saying that definition is a surmary in which ideas are ordered in relation to one another. For strict behaviorism, however, definition must be something else, for it does not recognize ideas. It would have to be something like a manipulation or arrangement of words to explain reactions and stimuli. Definition is largely a matter of classification. There are at least two effects that the conclusions of behaviorism will produce upon the problem of definition in logic. In the first place all definition will have to be made in terms of the physical organism, particularly the muscular and glandular systems. For example, Watson defines language as a "manipulative habit." Then he enlarges upon that by saying that "down in the throat at the level of the Adam's apple we have a simple little instrument called the larynx or 'voice box.' It is a tube made up largely of cartilege across which two very simple membranes are stretched (membranous glottis), the edges of which form the vocal cords. Instead of manipulating this quite primitive instrument with our hands, we manipulate it with its attached muscles as we expel the air from our lungs. . . We tighten the vocal cords, change the width of the opening between them as we tune the strings of the violin by turning the pegs. The air is expelled from the lungs through the opening between the vocal cords. This causes 
them to vibrate and to give out a sound. We call this the voice. But as we make this sound another group of muscles changes the shape of the throat, still another set changes the position of the tongue, another the position of the teeth, and still another the position of the lips. The mouth cavity above the larynx and the visceral cavities below constantly alter in size and in shape so as to change the rolume of the sound, the character of the sound (timbre), and the pitch of the sound. All of these responses are called into action the first time the baby cries." 13 That is language and that is all that language is, says the behaviorist. It is a very good physiological definition, but it is gi ven to cover all phases of language. Such a restriction of definition would be destructive of philosophy. Questions of ontology, cosmology, teleology and such would be ruthlessly pushed aside, for they cannot be reduced to the stimulus-response formula.

Another effect upon definition would be to explain one response or stimulus by substituting another term and so to reason in a circle. Thus "the behaviorist claims that there is a response to every effective stimulus and that the response is immediate. By effective stimulus we mean that it must be strong enough to overcome the normal resistance to the passage of the sensory impulse from sense organs to muscles." 14 Just when is 
the resistance normal?

Another example of such shifting of terms in definition is seen in the behaviorist's way of disposing of instincts. He insists that there are no instincts. But he sees a number of 'unlearned' responses, such as sneezing, hiccoughing, crying, smiling, grasping, the fear response, and some others. Two of these, grasping and fear, he treats very much in the same manner as others would in calling them instincts.

The other general basis of the behaviorist's deductive reasoning is his group of general assumptions. Perhaps his basal assumption is that nothing exists beyond the observing apparatus of the scientist. Right proudly does he boast that the scientific attitude is that of the observer, and so he qualifies himself as a scientist. He observes the child, watches him grow in behavi or from simple to complex, and draws the conclusion that the child that he sees, the organism, is all the child that there is. Logic ealls that begging the question, reasoning in a circle. For an example, let us return once more to the explanation that the behaviorist gives of thinking. On the stimulus-response platform he explains that it is subvocal speech. Watson $^{15}$ gives as part of his evidence an experiment with a man who was asked to think aloud in solving a problem. He observes that the man's behavior in reacting with 
words is quite similar to the rat in the maze. He started out slowly, then went hurriedly on a trial solution, stopped, came back to the starting point and began all over again. The rat worked with his feet, his whole body being actively engaged in the project. The man worked with words, his entire body being implicitly involved in the action. Now there you are. The premise is that man is only physical, just like a rat or any other animal. Then you observe the rat solve a problem by trial and error. Then you hear a man think aloud, using words, in solving a problem by trial and error. Finally you watch the man as he solves a problem without thinking aloud. Now you draw your conclusion that when he is thinking silently he is talking to himself, subvocally. And that is all that thinking is. "If then," says Watson, "you grant that you have the whole story of thinking when he thinks aloud, why make a mystery out of it when he thinks to himself?" quite so. If you grant that you have the whole story when he is thinking aloud you grant the main premise of behaviorism and there is no need of entering into the question of silent thinking. But suppose we do not grant this premise? The only thing that will be left of Watson's evidence will be a good instance of reasoning in a circle.

This premise of behaviorism includes the general 
assumption that there is no conscious element in behavior. That rules out the will, emotions and intellect. Yet when we read Watson's explanation of language he calls on us to initiate conscious behavior. In explaining the mechanism of the 'volce box' he says, "When you think of it, try to think of some simple reed instrument . . "16 Now how can a physical mechanism try to think? Thinking, says the behaviorist, can only come as a response to stimuli. If these stimuli come from within and we call on the mechanism to initiate the stimulus and bring about the reaction there must be some intelligence or power that controls the mechanism or organism. Even a player piano doesn't send forth music unless some power that is not the piano pediles it or turns on the switch. If, on the other hand, these stimull come from wi thout suppose some of us who read do not think of this simple reed instrument? Then the behaviorist would say that the stimulus was not "strong enough to overcome the normal resistance to the passage of the sensory impulse from sense organs to muscles." But, even with this flagrant bit of begging the question, he has called on us to help clear the way of resistance that the desired reaction might be stimulated.

In another connection Watson almost turns introspectionist in describing the process of building in manipulative habits on the basis of unlearned responses. 
Here is a behaviorist describing his own behavior (within the organism). He says, "We watch our chance and build upon these."17 He means that he controls his physical action. He is guilty here of two errors in logic. In the first place he employs the contrary of his premise to prove his premise. In the second place he uses a type of evidence, introspective, but he rejects it when used by others. Another phase of this general premise is the behaviorist's assumption that by reducing the physical to the minimum he can show that there is no mental. Thus he observes the behavior of the infant. The baby cannot tell us what he is thinking and so the behaviorist concludes that he is not thinking and that he has no capacity for thinking. He has no emotions, no will, and no intellect. He has only the capacity for making noise and that develops into the ability to talk. This line of reasoning overlooks two rather important fact.. One is that the mind grows as well as the body. Since the behaviorist accepts the law of physical growth he has no right to reject the law of mental growth. The other fact is that no one has yet discovered how much thinking (or what we have been calling thought) the baby does. In other words it is a question of how much potential behavior there is in the infant. It is the fallacy of assuming that any phenomenon can be explained 
away by reducing it to a minimum.

One other error in the logic of behaviorism may be mentioned briefly. It is what the logician calls argumentum ad ignorantiam. Thus the behaviorist says to the introspective psychologist, "I have rejected all conscious phenomena, now you prove to me that there is conscious activity." 18 one of the behaviorist's main arguments is an attack on subjective psychology.

III. Induction.

Modern science greatly strengthens its method by using both deduction and induction. Two good methods correctly used will add strength to any system. Two good methods incorrectly used will accentuate the weakness of any system. Behaviorism uses both deduction and induction. If behaviorism is true the behavioristic use of both methods must be correct and applicable in any field of study. Let us see where the behaviorist's use of induction leads.

Induction is reasoning from particulars to a general statement or law. It is the method by which we generalize concerning more cases than we examine. The greater the number of cases examined the more trustworthy will the conclusion be. A conclusion is not reliable that is based on just one or two experiments unless it is a crucial experiment. Indeed it has always been a question 
whether certainty can be gained through induction. Aristotle said that it couldn't, unless it be complete induction and, of course, that is enumeration and not induction at all. Logicians now do not claim that induction gives certainty. They say it gives probability only. The degree of certainty is heightened by the number of cases examined and the thoroughness of the examination. On the contrary, "false generalization due to haste and lack of critical examination is the constant danger which threatens induction." 19

This is the danger that faces behaviorism when it seeks the mental in the physical and, failing to find it, generalizes that there is no mental. It is the error of going into a closed room and after a brief examination of the contents of the room concluding that what is there exists and what isn't there does not ex1st. As well may a behaviorist train his microscope upon a drop of water and failing to see stars and planets conclude that astronomers are all wrong, and that there are no planets. Or the astronomer may conclude that since he does not see microbes through his telescope there are no microbes. The behaviorist shuts himself in a room where he can only observe the outward behavior of children and concludes that what he does not observe does not exist.

It is after some such fashion of reasoning that the 
behaviorist draws the conclusion that thinking is nothine but subrocal talking. When Titchener raised the question some years ago of how the behaviorist can know that there is any such process as thinking going on, since he cannot directly observe it, Watson answered that it can only be done by a logical inference. "In those cases where the response to the stimulus is not immediate but where it finally occurs in some form of explicit verbal or manual behavior, it is safe to say that something does go on, and that something is surely not different in essence from that which goes on when his behavior is explicit."20 Here is the behaviorist's inductive reasoning laid bare. With a bold "it is safe to say" he draws a conclusion that must revolutionize psychology, philosophy and logic. If it is safe to draw such important conclusions on such flimsy evidence we may as well throw away our logic. Why isn't it just as safe (or safer) to say that when one is talking in his effort to solve a problem he is merely expressing a process that is going on in his mind, and that when he does not talk the process is going on wi thout expression? As further support of his induction Watson tells of handing a friend a cigarette case that could only be opened by pressing a secret spring. After fumbling around for a long while he is put in a room by himself and told to come out when he opens it. After a while he comes 
out smiling and with the case opened. "Since there are no marks of violence on the case, the behaviorist, utilizing logic, has a right to assume that the subject continued to work at the problem as he had been trained to work at such problems and that his behavior in the empty room was essentially the same as that exhibited by him when he was under direct observation."2l Now, what is the logic that he utilizes? It is this, he assumes one thing and then from a rather superficial experiment he infers what he has assumed.

In similar strain he employs the evidence of a deaf, dumb and blind woman who, after being taught a hand and finger language, was observed in her sleep talking to herself using the finger language with great rapidity. 22 Once again he generalizes on one case and says that all thinking is implicit language activity, sensori-motor in character. Someone has told the parable of a family of mice that lived inside a piano. They saw the hammers rise and strike the wires and they heard music. They generalized and said that music is nothing but a mechanism of hammers and wires. But one day a philosophical mouse went outsi de the piano and observed the musician fingering the keyboard and he concluded, logically, that the music was caused by some person striking the keys, which caused the hammers to rise up and strike the wires and start vibrations that we call music. Now * Adajeted prom ds. 
the behaviorist observes the mechanies of the piano but shuts his eyes to the one sitting on the bench playing. That brings up the question of causality that, if it is not properly answered, may easily give rise to a false generalization. One form of the error in this connection has been called post hoc ergo propter hoc. That is sequence is accepted as a cause. Here is a stimulus followed by a response, ergo, the response was caused by that stimulus. A behaviorist tells of a dog rushing violently upon a child, barking loudly, and pouncing upon him and throwing him down. The child cries. The behaviorist says that the loud noise was the stimulus that produced the crying response. He then generalizes and says that loud noise is the only stimulus that always produces the fear response in infants.

This is very interestingly demonstrated in the way the behaviorist explains attention. He prefers to use the word selection, for he says it does not imply consciousness. Then he observes that a person responds to a blinding flash of light by jumping and screaming. A more moderate flash of light would call forth a more moderate response. Then he generalizes that the intensity, extensity, duration and movement of stimuli are factors in selective behavior. If there is any further difference it is due to the structure of the organism. "Birds fly, fi shes swim, snakes crawl, and men walk because of 
their respective structural characteristics. Obviously the stimuli responsible for these activities are selected by receptors structurally adapted for such functions." 23 This same line of argument he will follow in explaining differences in behavior among men. Two men affected by the same stimulus respond differently. The difference must be due to the difference in the structure of the two organisms. As a rubber ball will rebound farther from a tennis racquet than from a tennis net, so the cause of selective behavior is the stimulus plus the condition of the organism at the time, because the stimulus cames before the response.

Our conclusion of the whole matter is that behaviorism does not have a constructive contribution to make to logic. If behaviorism is true thinking and reasoning are entirely outside the realm of logic. In fact there is no thinking in terms of logic. Yet the behaviorist used induction and deduction in developing his system. He uses them and then abolishes them. In fact, he abolishes them in his use of them. Even if we accept the behaviorist's use of induction and deduction, we would only have a system of convenience. We could reason as the radical behaviorists do and prove any theory. Behaviorism destroys all standards and principles in logic. 
RETERENCES, CHAPTER III

1. R. W. Sellars, "The Essentials of Logic," p. 12.

2. Dewey, "How We Think," p. 1,2.

3. J. B. Watson, "Behavi orism," pp. 191,192.

4. Ibid., p. 193.

5. Ibid., p. 203.

6. K. S. Lashley, "Behavi orism and Consciousness," Psychological Review, 1923, p. 266.

7. Ibid., p. 268 .

8. J. B. Watson, "Psychology from the Standpoint of a Behaviorist," p. 348 f.

9. J. B. Watson, "Behavi ori sm," pp. 189,190.

10. Ibid., p. 179.

11. J. B. Watson, "Psychology from the Standpoint of a Behaviorist," pp. 110,111.

12. R. W. Sellars, "The Essentials of Logic," p. 27. 13. J. B. Watson, "Behaviorism," p. 181.

14. Ibid., p. 14. 15. Ibid., p. 197.

16. Ibid., p. 181. 17. Ibid., p. 185. 18 Ibid., p. 16.

19. R. W. Sellars, "The Essentials of Logic," p. 226. 20. J. B. Watson, "Psychology from the Standpoint of a Behaviorist, " p. 351.

21. I bid., 
22. J. B. Watson, "Behavi orism," p. 193.

23. Perrin and Klein, "Behavioristic Psychology," p. 80. 
CHAPTHR IV

BPISTEMOLOGICAL IMPIICATIONS

I. The nature of truth.

1. Various definitions and theories.

(1) Reali $\mathrm{mm}$ and (2) Ideali sm.

(3) Absolutism. (4) Absolute-relative.

$\begin{array}{ll}\text { (5) Copy. } & \text { (6) Representative }\end{array}$

(7) Correspondence. (8) Intuitive.

(9) Absolute mind. (10) Pragmatiam.

2. Behaviorism's definition.

3. Postulates of knowledge.

4. The problem of meaning in relation to behaviorism.

II. The Acquirement of knowledge.

1. Review of theories.

(1) Rationalism.

(2) Rmpiricism.

(3) Kant's modification.

(4) Skepticism.

2. The behaviorist's view.

3. Self-transcendence and hypothesis.

Conclusion 
CHAPTER IV

EPISTHMOLOGICAL IMPLIC ATIONS

Epistemology is one of the most difficult of the philosophic studies. That it rightly comes in the general realm of philosophy nearly all agree. Yet Durant, in his recent and very popular book "The story of Philosophy," very curtly dismisses the entire subject. He turns it over to psychology without any reservations whatsoever. In this he is rather an exception, perhaps yielding to a desire to attract popular interest to philosophy. To say the least, for philosophy or psychology, it is a perplexing subject.

It takes as its subject a study of the nature and conditions of human knowledge. The function of psychology in epistemology may be distingui shed as the study of the knowing mind, or the knowing powers of the organism (structural psychology); or the study of the development of cognition (genetic psychology); or an analysis of the part knowledge plays in the human life (functional psychology). The function of philosophy in epistemology is to reflect upon the origin, validity and limits of knowledge. It is readily seen that the two phases of the problem of knowledge intermingle and over- 
lap, and that a deviation from the generally accepted principles and methods of one must naturally affect the other. Thus our interest here is in the problem of a behavioristic epistemology. That there is such a problem goes without saying.

Epistemology assumes the possession of knowledge, as do all the sciences. Then it turns about and examines the basic elements of knowledge, as none of the other sciences do: what is knowledge? whence does it come? how do we get 1t? and how may we be sure of its validity and certainty after we have it? These are some of the questions involved in the general theory of knowledge. The sciences assume that we have knowledge and that what we get is reliable if it meets certain standard tests, without going into the generally basic theory of those tests. Psychology, being part science and part philosophy, is involved in this problem. And behaviorism, claiming to be only science and yet involving itself through its negations in philosophy, brings up certain very interesting questions. Some of these we are to consider.

Heretofore epistemology has been dealt with as a reflective study. But in the language of behaviorism it must be a manipulative study. The organism manipulates its store of word substitutes around the general problem. of knowledge. When the intraorganic stimuli that raised. 
or sustain the problem die away the response of manipulation ceases and the result is behaviorism's contribution to epistemology.

\section{The nature of truth.}

There is nothing directly stated in the behavioristic system concerning the existence or subsistence of truth as such, but there is much implied. As we come to the conclusions which these implications lead us to we may test the main theories concerning the nature of truth, which have been advanced by the philosophers through the ages, by thern. Realism is the theory that champions the objective existence of truth independent of human experience. It is just the opposite of Idealism, which claims that truth is a quality of the ideas of the mind and that apart from these ideas truth does not exist. The former is based upon philosophic dualism, while the latter is largely monistic. As was seen in Chapter II strict behaviorism excludes both. It is conceivable that the behaviorist might hold a type of monistic realism. That is, he would accept the fact of the objective existence of truth if you mean that it exists as physical objects. But all realists would insist that there must be something more than the objects as such, there must be quality or relations of some sort which could be appropriated by the mind yet which would exist 
independently of the mind. No form of Idealism could be tolerated by strict behaviorism, for the latter excludes all 1 deas when it excludes the mind and conscious activity. Absolutism holds that truth exists before we acquire it, that it always has existed and will continue to exist whether we ever possess it or not. We gain possession of it gradually. Then there is the absolute-relative theory, which says that truth is both absolute and relative. It is absolute in the sense that it is independent of human apprehension. It is relative to the extent that the human mind grasps it, and to the extent that every object presents an appearance that differs according to the differences in the constitutions of the percipients and according to the relations in which the object stands to other objects. Behaviorism would say that we cannot say anything one way or another about absolute truth. It is useless and meaningless speculation. We can only know or know about objects that stimulate us and to which we react. And so the behaviorist would reject absolute truth in all forms. He might hold to a theory of relative truth, but not the absolute-relative theory.

The copy theory holds that what we get is a copy of realities. Our ideas of objects or events are copies of those objects or events. This, however, would imply an absolute existence of truth, which the behaviorist 
would reject. He would agree that the words which he uses as substitutes for objects are indicators of the objects, but he would deny that there are such events as ideas concerming the objects, and would thus deny the copy theory. The representative view is that our ideas represent objects in their true relations. As these ideas re-present the objects to us we come to understand the objects in their constitution and in their relations more fully. That is truth. Again the behaviorist would say that if you mean that the reactions represent the stimuli then he would accept this theory. But he would deny that he gets any ideas or mental images of the objects. And so truth would be representative to him only as he manipulates his "voice-box" in the repetition of word substitutes for objects.

The correspondence theory is that our ideas correspond to truth. The ideas that we have of objects correspond to those objects in their true relations. This, however, implies some sort of absolute existence of truth, and it would call too much for $i$ deas for the behaviorist. The intuitive theory is that we have truth in our minds independent of experience. It is axiomistic with us. This the behaviorist would reject outright for he says that human behavior is largely learned and that we do not have a mind to intuit truth. Then there is the theory that truth is what God or an absolute mind accepts. As 
will be shown in the last chapter the extreme behaviorist must logically deny the existence of God. Certainly, if we have no evidence of finite mind we can get no evidence of an infinite mind.

The pragnatists say that truth is the workability of ideas, that it is a quality of propositions. "True ideas are those that we can assimilate, validate, corroborate, and verify. False ideas are those that we cannot. That is the practical difference it makes to us to have true ideas; that therefore is the meaning of truth, for it is all that truth is known as. The truth of an idea is not a stagnant property inherent in it. Truth happens to an idea. It becomes true, is made true by events. Its verity is in fact an event, a process, the process namely of its verifying itself, its verification. Its validity is the process of its validation." I

Pragmatism is a very practical and workable theory of truth. Since it is the aim of the behaviorists to make psychology simple and practical, non-speculative and non-metaphysical, it would seem that pragmatism and behaviorism would go hand-in-hand. And they would but for one small obstacle, namely that behaviorism can't support any system that builds upon ideas. Now, if we could change the terminology of pragmatism without destroying the principle of it we might effect an agreement 
between the two. Suppose we say that truth is the workability or agreement of unstriped muscular responses? Is that pragmatism without ideas? We might at least call it behavioristic pragmatism.

We would have to come to some such definition of truth or permit behavioriom to rule out all theories of knowledge, for everything must be explained in terms of stimulus and response. Accepting this definition for the time being let us first see how it affects the postulates of knowledge. Sellars ${ }^{2}$ gives a partial list of four general postulates: (1) that knowledge does occur; (2) that the world has a determinate nature which can be comprehended, partially at least, in thought; (3) that the world is essentially the same for all observers; (4) that individuals can communi cate and can mean essentially the same by their terms. The behaviorist would accept the first one without hesitation. For he is anything but an agnostic. He is too dogmatic for that. Furthermore he would not step into such a philosophical difficulty as to claim to know enough to deny knowledge. He would accept the second postulate, but he would insist that we comprehend through visceral response rather than through thought. The third he would accept, provided all observers are behaviorists. Certainly the world is not the same for introspectionists and behaviorists. The fourth he would accept and more. He would say that all 
individuals can be trained or conditioned from infancy to communicate with the same terms and contents.

It may be objected that this is making too much change in these postulates. But they must be modified to suit our definition or be rejected entirely. But that brings up the problem of meaning, a fundamental, as well as a dificult, problem in psychology and philosophy. Meaning is the content that we put into terms, or that terms have for us. Words change their meaning as people change their use of them. Take, for example, the Inglish word 'let.' It means, signifies, exactly the opposite of its original meaning. We talk about the meaning of an event or a word because it carries with it certain signs that point to other events and words, or because it produces certain results, or necessitates certain types of action. The behaviorist says that meaning is a useless term. It is another one of those terms that have been used so long by introspective and functional psychologists that they cannot be made to fit into the behaviorist's scheme. And yet a compromise is possible on the behaviorist's conditions. "If you are willing," says Watson, "to agree that meaning is just a way of saying that out of all the ways the individual has of reacting to this object, at any one time he reacts in only one of these ways, then I find no quarrel with meaning. " 3 In another place he says, "from the behaviorist's 
point of view the problem of 'meaning' is a pure abstraction. It never arises in the scientific observation of behavior. We watch what the animal or human being is doing. He 'means' what he does." 4 If it never arises in the observation of behavior it is because he assumes it or speaks of it in other terms. When the behaviorist talks of predicting behavior he is projecting or extending the meaning of responses in relation to stimuli. But the general effeat of Watson's definition of meaning, if it be accepted in full, is to further mechanize any theory of knowledge that the behavioriat may have.

II. How knowledge is acquired. Sellars 5 suggests that the claim to acquire or attain true knowledge implies four things: (1) "the ability to obtain significant facts-that is, facts which are capable of revealing something about objects; (2) the right to use past experience so far as it is relevant; (3) the value of mental operations like analysis and construction as means for deciphering the structure or constitution of objects; and (4) the assumption that the world which we claim to know has a pattern or constitution which is in some measure reproduced in facts and grasped in ideas." These are the implications of knowledge. The facts of science must have significance 
as to the structure of nature. To get knowledge is to obtain these facts, and then classify and interpret them-discern their meaning. As there are various theories concerning the nature of truth so there are different theories as to how knowledge is acquired. We may well examine them and see which comes nearest harmonizing with the conclusions of behaviorism. The first to be noticed is rationalism, or dogmatism as Kant termed it. It places implicit confidence in the ability of the reason to fathom the nature of independent reality. It asks no mandate from some higher authority to prosecute its ends. What it regards as necessary and universal is necessary and universal. It assumes that reason is a peculiar function equal to its task of knowing the universe. The difficulty is that reason is so often unsuccessful. The problem of knowledge is closely connected with the problem of error and ignorance. Reason alone is not always capable of making and verifying the distinction.

Empiriciam holds that all knowledge comes from experience. It denies the existence of any a priori constituents in knowledge, maintaining that at first the mind is a blank tablet or clean slate, upon which experience must inscribe all the characters. These inscriptions come one by one, and what seems to be a necessary connection appears so only from the habit we 
have formed by associating certain elements together. In recent times there has developed a more flexible empiricism, in which the experience does not have to come in a piecemeal fashion, or as an accidental accumulation of psychic elements. Thus William James called his philosophy a "radical empiricism," distinguishing it from traditional empiricism by the fact that the latter "has always shown a tendency to do away with the connections of things and to insist most on the disjunctions," while his own empiricism "does full justice to conjunctive relations, without, however, treating them as rationalism always tends to treat them, as being true in some supernal way, as if the unity of things and their variety belonged to different orders of truth and validity altogether." John Dewey calls his an "immediate empiricism," It "postulates that thingsanything, everything, in the ordinary or nontechnical use of the term 'thing'-are what they are experienced as. Hence, if one wi shes to describe anything truly, his task is to tell what it is experienced as being." Experience is thus a method, the mothod, of acquiring knowledge. Knowledge is itself a form of experience. The rationalist objects that he can gain knowledge through his reason independent of experience. 6

Kant sought a modification and reconciliation of 
rationalism and empiricism. He adopted the basic view that whatever is given in experience is purely mental in nature, or, at least that it is constituted materially of sensations. Objects must be related in thought. Knowledge is impossible without a thinking mind, that is, without understanding or intelligence. Reason is not only receptive, but active. Intuition is perceptual, understanding conceptual. Knowledge consists in synthetic judgments a priori. "Analytic judgments are always a priori; we know without going to experience that all extended things are extended; such judgments are based on the principles of identity and contradiction. But they do not add to our knowledge. Synthetic judgments a posteriori add to our knowledge, but are not sure; the knowledge they yield is vague, uncertain, problematic. We demand apodictic certainty in our sciences, and such certainty is possible only in synthetic judgments a priori."7 And so empiricism and. rationalism may yet come together in the attainment and systematization of knowledge.

Another attitude toward the problem of attainment of knowledge is that of the skeptic. He either says that there is no knowledge, or if there is we cannot know of it or acquire it. He usually does not deny the existence of knowledge as a fact of experience, but he questions seriously most theories of knowledge. He has a 
theory of his own about knowledge, which is mainly a denial of other theories.

Now, what assistance can behaviorism render in solving the problem of how knowledge is acquired? As to the four things that Sellars says are requisite to the acquirement of knowledge strict behaviorism would have the following to say: (1) we have the ability to receive stimuli from objects and to carry those objects, or their equivalents in word substitutes, around with us; (2) we have the right to use past experience, which is merely a manipulation of conditioned responses which have become habitized or made prominent through frequency or recency of repetition; (3) mental operations have no value in analysis or anything else, but the visceral and glandular systems respond to the stimuli, of the various elements of the objects and to the intraorganic stimuli in such a way as to lead to a deciphering of the structure of objects; (4) we can make no assumption concerning the pattern of the world, we can only react to the stimuli which come to us from the world as it is and as it affects us. And so the behaviorist would claim that we can get knowledge without the use of a mind through physical responses and retention of those responses by the organism.

As to the theories stated above, strict behaviorism would reject rationalism, for it does not recognize 
reason apart from stimuli and response. Kant's modification of rationalism and empiricism would likewise be set aside by radical behaviorism, for it knows no compromise on the question of mental phenomena. The behaviorist may be a skeptic to the extent of doubting, even rejecting, all theories of knowledge except the one which builds upon his platform, but he would not be a skeptic in the sense of denying that we can get knowledge. He says that we get knowledge concerning the objects to which the organism reacts, but that it does not come through any faculty such as mind, or reason, or consciousness. Knowledge has been defined as the apprehension of objects. The behaviorist would say that, accepting that definition on the basis of the stimulus-response formula (that apprehension is a function of the physical organism), he gains knowledge. When the intraorganic stimuli, that center in the apprehension of the object, die down the knowledge is acquired. These stimuli naturally, or mechanically, arise as the object, through its word substitutes, is being organized into the unstriped muscular system of the body. Then the recall of that bit of knowledge is a manipulative response to some other stimulus, the manipulation being vocal or sub-vocal speech.

So it would seem that the behaviorist would follow out his conclusions in epistemology to empiricism. of 
course it would be empiricism with his modifications, he would be a behavioristic empiricist. He agrees with the traditional view that the mind at birth is a blank page or clean slate upon which the characters are to be written-only he would say it is the physical organism, and not a mind, that is at birth unconditioned but ready to be conditioned by the stimuli that it meets. Experience, for behaviorism, is only reaction to stimuli, it cannot involve any mental interpretation or classification of those stimuli or responses. That opposes Jame' primary claim that cognition is a function of consciousness. The behaviorist would say that it is a manipulative function of the vi scera and glands.

This position also eliminates the element of selftranscendence in getting knowledge. The physical organism has no power to transcend itself, it can only receive the stimuli that come to it though they may come from ever so great a distance. And so when my friend from interior Brazil tells me of his home, his work and conditions there, I claim to react by seeing mental pictures as he describes them, though I have actually never been to Brazil. Then, three months later, I sit down and give myself over for a few minutes to an imaginary visit with my friend at his home in Brazil. Now the behaviorist says that I am merely 
manipulating the word substitutes for those objects which he gave me. But I would remind him that there is no new stimulus now calling forth that manipulation, and that those words stimulated me through my ears, and not through my eyes, but that now I can see the adobe home and the orange trees around it. But that is introspection and he dismisses that as unworthy evidence.

If there is no self-transcendence one wonders if the behaviorist can formulate a working hypothesis concerning something that has not been discovered. His reasoning consists of manipulation of word substitutes. In order for this thinking to take the form of an hypothesis his manipulation must take the form of conjecture concerning the relations which hold between facts or lie back of them. The behaviorist would claim that he does that in his trial-and-error thinking. It may be granted that hypothesis is trial-and-error thinking, but it must be admitted that it is a rather advanced and highly developed form of such thinking. That strict behaviorism does not lead to such a type of thinking as we call scientific hypothesis we call Watson's language in to show. He is discussing how the 'new' comes into being, how we get new verbal creations. "The answer is," he says, "that we get them by manipulating words, shiftine them about until a new pattern is hit upon. . How do you suppose Patou builds a new gown? 
Has he any 'picture in his mind' of what the gowm is to look like when it is finished? He has not, or he would not waste his time making it up; he would make a rough sketch of it or he would tell his assistant how to make it. "8 This type of hypothesis which he says cannot take place has happened many times, according to his own conditions. A good example is seen in the discovery of the planet Neptune. Uranus was observed to be out of position according to previous calculations. Adams in Fngland and Leverrier in France then proposed the hypothesis of another planet affecting Uranus. They proceeded to chart the course of the planet they deduced (the thing that Watson said Patou would have done had he worked according to a picture in his mind), and on the basis of their calculations they found that it should appear at a certain time and in a certain position. At that time Galle, of Berlin, trained his telescope and for the first time observed the planet which they named Neptune. It was in almost exactly the place indicated in the chart. The behavioristic astronomer would have looked first at this star and then at that until accidentally he mi cht have observed the new planet, but he would never have charted its course beforehand.

To what extent, then, can the strict behaviorist acquire knowledge? A. 0 . Lovejoy says that "if per- 
ceiving and thinking are what Vatson says they are, and nothing more, no organism can ever know either what it is doing or what object evokes its response; and therefore no psychological investigator can possess such knowledge. The only consistent behaviorist would be one who knew nothing whatever-who at no moment of his existence could do more than relax or contract his muscles, vithout being aware that he was doing so. And to maintain even a decent semblance of consistency the behaviorist should at least refrain from professing to know anything. " 9 Perhaps Lovejoy is a bit positive, but there is ground for his general claim. It is simply a matter of requiring of the behaviorist what he requires of others.

We must conclude, then, that epistemology for the behaviorist is just another phase of the behavior of the physical organism. Truth is the agreement of extraorganic and intraorganic stimuli with their responses. When this agreement is reached knowledge has been attained and the organism ceases to function in that particular connection. Knowledge is thus conditioned upon the physiological changes of the body. 


\section{REFERENCES, CHAFTHR IV}

1. William James, "The Meaning of Truth," pp. v-vi.

2. R. W. Sellars, "The Essentials of Logic," p. 311.

3. J. B. Watson, "Behaviorism," p. 201.

4. Idem, "Psychology from the Standpoint of a Behaviorist," p. 355 .

5. R. W. Sellars, op . cit., p. 318 .

6. This sumnary is partially taken from The New International Encyclopaedia, vol. 7, p. 710.

?. Frank Thilly, "A History of Philosophy," p. 397.

8. J. B. Watson, "Bahavi orism," p. 198.

9. A. 0. Lovejoy, "The Paradox of the Thinking Behaviorist," Philosophical Review, 1922, p. 146 f. 


\section{CHAPTER V}

\section{BHHICAL IMPLICATIONS}

I. Behaviorism and the problem of moral value.

1. The meaning of value.

2. Theology and Formali sm.

3. Kant1 an Formalism .

II. Hedonism and perfection.

1. Modern Hedonism.

2. Psychological and ethical Hedoni sm.

3. Behaviorism and perfection.

III. Behavioristic virtue.

1. Conditioning or training.

2. Indivi duali sm and over-individuali sm.

IV. The problem of freedom.

1. Determini sm and Indetermini $\mathrm{sm}$.

2. Behavioristic Determinism.

3. Responsibility and punishment. Conclusion. 


\section{CHAPTER V}

\section{ETHICAL IMPLICATIONS}

Ethics is that branch of philosophy which takes as its field the study of morality. It studies human conduct with reference to moral rightness or wrongness. Moral conduct is the voluntary action of a person in so far as that action is amenable to a standard of obligation imposed on him by soclety. The plan of life derived from that standard of obligation is always first adopted by the individual from the community in which he is reared, but it may later be modified by his intelligence, emotions, will and personal experience. As to what there is in the standard of obligation that makes the conduct that measures up to it moral and the conduct that is contrary to it immoral, we shall have to determine by examining into the various ethical theories.

Ethics is a branch of philosophy separate and distinct to itself, yet it has important connections with all other branches. It is a study of values based on experience rather than metaphysics. Everett points out that "ethics precedes and leads up to metaphysics rather than follows its completion. The central reason for believing in the logical priority of ethics is that all 
those values with which ethics has to do are developed in the historical life of man, and are disclosed to our knowledge by methods of observation and analysis that are essentially scientific. Metaphysics has never discovered a new type of moral value." I To say the least, ethics is in its own rights in the study of : moral values and, while it may draw assistance from metaphysics, it relies largely upon the experiential method. Therefore psychology should be of material help to ethics. Psychology should do more than explain mind in the sense in which other sciences explain their material, for it deals with material that has in some sense at least a philosophic content. It should leave room for anthropocentric values, for human ideals and aspirations, and it should present its material in such a way as to identify its principles with some qualitative elements in our experience. Whether or not behavioristic psychology does that we may see from our study. Watson regards ethics at present as tending toward "experimental ethies based entirely upon behavioristic methods." 2 It is to be remembered that there may be a deal of difference between experiential and experimental ethics.

I. Behaviorism and the problem of moral value. A value is a principle of preference. A moral value 
is a positive principle of preference that looks to the good, the welfare of the community. An immoral value is negative in the sense that it tends toward evil and is undersirable for the community, not in the sense that it negates value. We live in a world of values: economic, bodily, recreational, associational, character, aesthetic, - intellectual and religious. To live the virtuous life we must choose aright among these values, which, said Plato, we must know not only singly, but in the relations which they sustain to each other and to the purpose of life as a whole. Morality is to be 1 dentified with the recognized virtues such as temperance, truthfulness, justice, benevolence, etc. These moral values are distinguishable only by conscious beings, or, we may say, to beings who exhibit the equivalent of conscious activity. The good is presented to us in a satisfying manner, we are pleased with it. Evil is presented to us in a way that does not satisfy, we fear and resist it.

That brings us to the question of what is good. What is the summum bonum which stands as the good of all human endeavor? Is it to be found in some end to be attained? Or is it some primary element in the idea of duty that is dictated by some universal law of right? The theologists in ethics affirm that the rightness of an act depends upon the intention and the effects which 
the act produces. Acts are objectively right when they result in the betterment of society, wrong when they produce social misery. Formali $\mathrm{sm}$ in ethics discovers the rightness of acts in the will, the desire, regardless of the results or ends achieved. Values are thus determined by the relative strength and rectitude of the desires, by the degree of loyalty to a command or law of unconditioned authority.

In the difference of attitudes toward this universal law, or standard of obligation, we may discern the characteristic distinctions of some of the leading ethical theories. It marks the distinction between individuali sm and over-individualism which will be noted later in this chapter, and which was the difference in ethics between Socrates and the Sophists. Plato taught that this immutable essence of morality is the eternal supreme "form of the good," the supreme authority in a hierarchy of ideal essences. Aristotle said that morality consists in certain obligations imposed by the desire to secure certain ends. Christian theology says it is God's law of righteousness. Pthical intultionism finds a "faculty" of conscience in every man; a faculty which may become atrophied in those who refuse to give it play, but which is an always present element in the original equipment of faculties possessed by every man. 
Fthical rationalism, as championed by Kant, ascribes to pure reason a constant and invariable mandatory activity, which operates in every individual to the production of a recognized obligation to do certain things and not to do certain other things, simply because this doing or not doing is pure reasonableness. This was Kant's conception of the moral law, his categorical imperative. He formulated it in the principle "Act only on that maxim whereby thou canst at the same time will that it should become a universal law." It has its seat and origin in a priori reason.

Is behaviorism interested in the problem of moral value? Watson says he is not. In describing his method of discovering the personality of an individual he says, "the behaviorist is naturally not interested in his morals, except as a scientist; in fact he doesn't care what kind of man he is." ${ }^{3}$ But this is an extreme position, and is perhaps due to Watson's enthusiastic desire to be strictly scientific and to hold within the area of behavioristic psychology. But he has already defined behaviorism in such terms as to include all human behavior, and has sallied forth to define ethics in terms of behaviorism-that it is experimental ethics based entirely upon behavioristic methods. Putting these two statements together we can certainly draw the conclusion that there is no place in extreme behaviorism 
for a system of moral values.

$$
\text { II. Hedonism and perfection. }
$$

Hedonism roots the universal, unvarying form of morality in the desire of every individual to secure pleasure. It gets its name from the doctrine of pleasure, being $\eta \delta$ or $\eta$, hedone. It was at first egoistic but gradually became altruistic. In modern form it is best represented by Hobbes, Locke, Hume, Paley, Bentham, and Mill. Locke claimed that it is Man's proper business to seek Happiness and avoid misery." Mill set forth a theory of universal utilitarianism based upon the golden rule of Jesus of Nazareth. And so the scope of hedonism has gradually widened until it has included all the ideal satisfactions of human life, even those states of spiritual satisfaction which attend the noblest and most unselfish activities.

Just here the distinction between psychological and ethical hedonism should be pointed out. It is a distinction between motivation and valuation. The motive in the pursuit of pleasure is the psychological aspect of hedonism, while the value is ethical. The psychological view is prospective, emphasizing the motive, that which is desired. The ethical view is retrospective, emphasizing the value, that which is desirable. For the former pleasure is the motive of every 
act, while for the latter the value of conduct is ult1mately measured by the production of pleasure. Now, if the behaviorist should recognize any motive power at all in human activity it would seem that he would accept psychological hedonism. If pleasure is the satisfaction of intraorganic stimuli, satisfaction being the act of naturally allaying those stimul1, then for the behaviorist pleasure is the motive of every act. It is that which moves the workman to do just enough work to get his week's pay. But the behaviorist would not be an ethical hedonist, for he does not recognize any principle of preference which would make one pleasure more desirable than another, and another most desirable. True it is that one pleasure will more nearly satisfy the intraorganic stimuli than another, but there is no mechanism in the bodily system that classifies stimuli and responses into more desirable and less desirable. Any such function or faculty would come very near being conscious activity.

The ethical theory of perfection holds that the end in view in all conduct, the highest good, is the development of inherent capacities, a process of selfrealization. For the behaviorist these capacities can only be realized in behavior, and so perfection is a perfection of behavior. In this case the standard is entirely physical. However, behaviorism will have to 
surrender all claims to the perfection theory for it requires a faculty of knowing the capacities of the organism and the stimuli to be chosen which will best develop his capacities toward perfection, according to strict behaviorism, but it would not be the result of a plan of perfection worked out beforehand, it would only be a matter of chance, something of the trialand-error sort, and that is not ethical perfection.

III. Behavioristic virtue.

In judging ethical conduct we take into consideration both the subjective and the objective elements. Conduct is sometimes valued according to the intentions, desires, will that form the subjective aspect of conductformalism. But more usually we place a value upon conduct according to the effects or results accomplishedteleology. In behaviorism, while there may be a subjective element consisting of intraorganic stimuli and responses, the only element that we can know and appreciate is the teleological. So for the radical behaviorist there is no formalism in conduct. What then is the ethical virtue of behaviorism? It is moral training, not training according to a system of moral values, but according to the reactions of the largest number in the group in which he is being trained. The behaviorist says that if we will take people while they are infants we can 
condition them, or train them, according to any standard that is set up. So if the standard is lofty the conduct, which will be the result of the conditioning, will be good. This training is the virtue of behavioristic ethics. The only fly in the ointment is the question of the standard. If a behaviorist could not erect a high standard for himself it is difficult to see how he could set up such a standard for others. Furthermore, if a behaviorist cannot desire or will to act according to a certain standard save as he responds to stimuli how can he desire or will that the child shall respond in a certain way which is in accordance with the standard, and not in another way which is contrary to the standard? But these are problems that the behaviorist doesn't recognize.

It was seen in Chapter II that the conclusions of behaviorism lead to a rigorous mechanistic world-view. The effect of such a view is that it commits us to a status quo, without any opportunity for real progress. The behaviorist talks about conditioning children to respond in such a way that their behavior will be standard, that is good and commendable. But that standard would have to be a mere summary of the stimuli and responses that have constituted our behavior. And these stimuli that we have responded to came down to us from the generation before us, and so on back. Where would any new, or 
better, standard begin? It couldn't begin without a creative intelligence to initiate it.

The general ethical conclusion then would be individualism rather than over-individualism. The standard for each person would be the harmony or agreement of his reactions to the stimuli that come to him from the group or that arise within his organism. The stimuli of social environment, or of law, would awaken certain intraorganic stimuli. When he does, or says, or says sub-vocally, the thing that causes those intraorganic stimuli to die away he has satisfied himself and has met all the standard that he knows anything about. This follows directly from Watson's definition of 'solution' quoted in Chapter III.

IV. The problem of freedom.

The controversy over the problem of freedom centers chiefly in two theories, determinism and indeterminism. Determinism is the view that all events in man's mental and moral life, as all events in the physical world, must be thought of as antecedently conditioned, of being the necessary sequence of preceding events in which they have their origin. This means that in conduct any act, whether good or bad, is the necessary result of the combined forces of the inner nature and environment of the one performing the act. Indeterminism is the view 
that there are events in the mental and moral if fe which cannot be explained as the necessary result of preceding conditions or relations. "These events spring immediately and spontaneously from the will, and appear in human experience as a strictly new creation." 4 It holds that the will is exempt from the principle of causation, that it is not determined by external compulsion, nor by internal compulsion; but that man has the natural ability to choose good acts, and that he may be influenced by ethical motives in making his choices.

Between the two theories the strict behaviorist would have to take the deterministic view. His platform eliminates indeterminism, for when you eliminate conscious activity you also eliminate will, which is one phase of conscious activity. Furthermore, the aim of behaviorigm is to be able to predict the response when the stimulus is known. That implies that the response is automatic, predetermined by conditioning, and that no element of contrary choice enters into the behavior. At least it implies that when one responds in a certain way to a stimulus he will always respond in the same way to that stimulus, under similar conditions, unless he is conditioned by some external power to do otherwi se.

The radical behaviorist insists that nearly all human behavior is learned, there being only a few physi- 
cal responses which he terms 'unlearned behavior,' on the basis of which he builds in the conditioned responses. The baby holds the bottle in his hands because they are structurally more suitable for that than his feet. He learns to speak Inglish because that is the language he hears his parents use. As he grows he learns to play the piano because his fingers are long and tapering and his parents require him to practise and be conditioned as a pianist. If he ever learns any other language besides English it will be because it is in the college or university curriculum, or because he meets certain foreigners, or because he travels in a foreign country. But man exhibits no instincts, no intuitive behavior, no conscience, no consciousness whatsoever. That is extreme determinism. Take, for example, Watson's explanation of habit formation. He says, "Some stimulus in the outside environment or in the inside environment sets the individual moving. He may move in many ways, do many hundreds of things, before he blots out stimulus A or moves himself beyond its range. If, when he gets into the same situation again he can accomplish the one or the other of these results more rapidly and with fewer movements, then we say he has learned or has formed a habit." 5 Now, if we can control the stimulus (which Watson claims to do in his experiments with babies) we can control behavior. Man's conduct, then, is 
determined by the stimuli of his environment or by previous conditions, stimuli and reactions.

As pointed out above, the strict behaviorist disclaims any interest in man's morals or moral conduct. Now, since extreme behaviorism would make of man a mere automaton, acting only as he is stimulated or conditioned to act, what would be the result upon the question of responsibility and punishment for crime in a social order? There would no longer be any emphasis upon "criminal intent." It would not be fair to punish the criminal, for he would say that he was conditioned by previous stimuli to respond in the way he did, and when the stimulus arose he had no power of choice, it was merely his organism reacting. Then if he is not responsible what right would society have to punish him, even by putting him in an asylum? Then those who were responsible for the environment, or the stimuli, under which the criminal acted should be held accountable. But they responded to certain stimuli to which they had been conditioned, there was no sort of "criminal intent" on their part. And so our investigation would go on back in an infinite regress. We would find no one responsible or accountable. Then we may as well do away with the courts and concentrate upon conditioning children so that they will not commit crime. But what organism is there that can rise above its environment, eject all element of 
crime and evil, and, wi thout any power of choice or judgment or conscience, condition children to live according to a new standard?

Extreme behaviorism, being hedonistic and deterministic, would nullify all moral codes and vitiate justice. Experimental and behavioristic ethics would be a matter of trial-and-error conduct without moral values of any sort. What advantage would there be in such ethics and where would it lead us? Perhaps it would be more consistent to say that extreme behaviorism would give us no ethics at all. 


\section{REFEREANCHS, CHAPTER V}

1. W. G. Everett, "Moral Values," p. 12.

2. J. B. Watson, "Behavi orism," p. 17.

3. Ibid., p. 217.

4. W. G. Everett, "Moral Values," p. 336.

5. J. B. Watson, "Behaviorism," p. 162. 


\section{CHAPTER VI}

\section{RELIGIOUS INPLIC ATIONS}

I. The soul.

1. The problem stated.

2. What science has to say.

3. What general non-behavioristic psychology says.

4. The testimony of philosophy.

5. Behavioristic view of the soul.

6. Criticism of the behavioristic view.

II. God.

1. The problem stated.

(1) Existence. (2) Character. (3) Relations.

2. Argument from science and philosophy.
(1) Design.
(2) Teleology.
(3) Universal

Phen omenon.

3. Argument from behaviorism.

(1) Objective method.

(2) Stimulus-response formula in revelation.

(3) Stimulus-response formula in relations with God.

(a) Behavioristic treatment of fear.

(b) Behaviorism and faith and trust. 
CHAPTER VI

III. Immortality.

1. Is it subject to scientific proof?

2. Ethical and religious value of the doctrine.

3. Conclusions from behaviorism.

Conclusion. 
CHAPTER VI

RETIGIOUS IMPLICATIONS

Religion is a recognition of a "power, or powers, upon whom we recognize our dependence and with whom we seek to establish and maintain a happy relationship. It is indissolubly related to philosophy for it is our effort to adjust all our theories of reality and ultimate cause on the basis of our belief in God. Philosophy seeks to unify the conclusions of all the sciences on the basis of some cormon principle or type-phenomenon. Religion seeks to use the conclusions of science and philosophy in personal relationship with the primal cause, the uncaused cause. Philosophy is the effort to unify knowledge, while religion is the effort or desire to utilize knowledge to satisfy the desires of the soul.

In a similar way religi on is related to psychology. It takes the conclusions of psychology and goes beyond them. It is possible for the two to be so understood as to make of psychology a support of religion. But often psychology is so treated as to be antagonistic to some of the fundamental claims of religion. The word "psychic" comes from the old Greek word $\psi \cup \chi \eta$, which meant mind or 
soul, and so psychology would be the science or study of the mind or soul. And so religion and psychology seem to have much in common. Psychology studies the mind or soul, while religion seeks with the mind or soul (or mind and soul) to acquire knowledge of God, holding that in the acquisition of that knowledge we gain the greatest happiness and blessing. Jesus, the founder of the greatest religion that the world has yet known, said, "this is life eternal that they might know thee, the only true God, and Jesus Christ whom thou hast sent." l

This etymological definition of psychology was adopted before behaviorism came upon the field. But because of its denial of the mind and consciousness we are interested in studying the effect its conclusions will have upon religion. Religi on is so intimately related to philosophy and psychology that it is deemed fitting to let the closing chapter of this thesis deal with it in a general way in connection with the claims of behavioristic psychology. Our study will be grouped around three main problems: the soul, God, and immortality.

$$
\text { I. The soul. }
$$

Is there a soul in man? If so what is the nature of it, of what stuff is it made? What are its functions? 
These questions, in brief, constitute the problem of the soul. We shall not go into the questions that religion per se is interested in, such as the redemption, the liberation, the growth, the sanctification of the soul, and such like. Our aim is to see if behavioristic psychology, assuming that its conclusions are valid, can affect the general claims of religion concerning the soul. Religion claims that man has a soul, that it is of spirit nature clothed for a period of time with a physical body, and that its functions are to worship and serve God its creator and to enter into happy fellowship with man its fellow creature.

The attitude of the physical sciences has been in the main to leave the question of a soul alone. Physical science deals with the phenomena that can be handled with its apparatus and makes no claims concerning the realm into which its apparatus cannot reach. It leaves that to philosophy and religion. Occasionally we find a scientist who makes bold statements concerning the soul or other questions in religion, but he does so as a philosopher or religionist and not as a scientist. Biology does not discover a soul, but neither does it affirm or deny the existence of a soul. And so with physiology, chemistry, physics and others. The problem of the soul is outside their realm.

Some types of non-behavioristic psychology have 
assumed the existence of a soul as in some way identified with or wrapped up in consciousness. As such they have dealt with its functions or faculties as threefold: intellect or reason, emotions or feeling, and will. Religion says that faith is an act of consciousness, but that it cannot be restricted to intellect, or will, or emotions as such. When religion goes on into the realm of faith psychology has assumed the attitude of noncommittal. True it is that some psychologists have advanced into the field of religion, some being favorable to the claims of religion while others are antagonistic. But they do so as psychological religionists and not as strict psychologists. Indeed there has grown up in the past quarter of a century quite a field of study called the psychology of religion. It should be clearly understood that religion is an open field for study. "To popular thought, the extension of scientific inquiry into the field of religious experience has sometimes seemed strange and even menacing. But the objection that religion is too sacred for investigation falsely assumes that the understanding of the facts of the religious life will destroy that life itself. . . When one enters the precinct of religion one does not leave the realm of law and order."2 The field is open to investigation, but science must remember that when it comes to facts, or phenomena, that are beyond the reach of its 
apparatus it is not entitled to dogmatize upon them. And in the main that has been the attitude of science. However, when psychology and religi on meet in a common study where psychological method and religious appreciation harmonize much may be accomplished. This is not a contradiction of the statement made above, for the religious appreciation carries beyond the psychological method in the study of religious phenomena.

Philosophy in general has recognized the existence of the soul, though there has been some disagreement as to its functions and immortality. There have been some materialistic and mechanistic philosophies that have denied the existence of the soul, but they have been more the exception than the rule. Philosophy has generally regarded the soul as the main mark distinguishing man from lower animals.

The extreme behaviorist is enough philosopher to have a theory concerning the soul and religion. The fact that his theory is mostly a negation doesn't alter the fact that he has a theory. The wide sweep that the behaviorist makes in defining his field makes it imperative that we shall examine his conclusions and statements as they reach over into the realm of religion. In discussing what he thinks is the religious background of current introspective psychology Watson says that people have always been controlled by fear stimuli and that 
religion has made use of that by imposing certain concepts on its adherents from infancy on. Then he says that "One example of such a concept is that there is a fearsome God and that every individual has a soul which is separate and distinct from the body. This soul is really a part of the supreme being. This concept has led to the philosophical platform called 'dualism." All psycholoey except behaviorism is dualistic. That is to say we have both a mind (soul) and a body .. No one has ever touched a soul, or has seen one in a test tube, or has in any way come into relationship with it as he has with the other objects of his daily experience." 3 This is the natural and the logical position for strict behaviorism to take since it has taken in his scope of study all human activity and at the same time has limited itself to the objective observation method. It seems illogical that such a self-styled 'scientist' should assume the whole realm of human action and then limit himself to one method of approach. However, having proclaimed such a platform he does well to hold to it and in holding to it he is logical. But he does not always do so. Let us see. Religi on is largely a matter of conviction, sometimes it becomes prejudice. Watson admitted in handling the question of thinking that since he could not observe a man manipulating certain organs within the body he had to infer that such was the 
case. In other words, in this instance the radical behaviorist must go beyond his objective method and draw a conclusion that is not supported by observation. But in the question of the soul he rules the whole matter aside by saying that it is a plain assumption, unprovable and unapproachable. 4 The first inference, concerning thinking, is 1 llogical while the second, concerning the soul, is logical according to his major premise or assumption. But why should he be guilty of such a flagrant distortion of logic? It looks very much like prejudice. He is ready and willing to use inference in supporting the hypothesis that thinking is sub-vocal speech, but he rants and raves if someone else wants to use inference in supporting the position that religion is based upon the real existence of a soul in man.

\section{God.}

The second problem with which we are faced in examining the religious implications of behaviorism is the question of the existence and the character of God and possible relations that man may have with him or that he may sustain with the universe. Here again the general attitude of physical science has been one of non-committal. Physical scientists have often committed themselves as in favor of, and some as opposed to, the idea of a supreme being who rules over the affairs of men and the universe. But physical science as a study 
does not assume the problem of proving or disproving the existence of God. Philosophy, however, takes the conclusions of science and draws certain inferences concerning God.

One of these conclusions has been based upon the evidence of desion in man and nature. Man's body is designed perfectly, showing supernatural intelligence in the designer. In like manner nature outside man shows marks of design that indicate supreme intelligence. Law and order are seen everywhere. The atom is maintained in order like a miniature solar system with its electrons whirling about a nucleus that is the center of gravity. The stars and planets are held in their orbits and systems by laws that seem immutable. There must be a God to design and sustain such law and order. Not all philosophers have agreed in such a conclusion, but it is in the province of philosophy.

A similar conclusion has been based upon the evidence of purpose in man and nature, teleology. Scientists and philosophers have discovered a purpose for nearly everything that they have discovered. Certain habits of lower animal life serve the purposes of higher animal life. Animate and inanimate nature may be used by man to accomplish certain ends. Whither does it all lead? Philosophy and religion have said that there is a higher purpose that is in the mind of God. 
In like manner the argument from "universal phenomenon" has been used. Wherever man has been found he has been found to have an idea of God. Certain philosophers have said that this indicates the existence of God. Man everywhere has the idea of a perfect being. Existence is a necessary attribute of perfect being. Therefore God must exist. Others have rejected this argument, saying that we might have an idea of a perfect island but that wouldn't prove that such an island exists. And the first group have answered that such is not a universal phenomenon. And so the argument has been used and criticised through the centuries.

It is not necessary to go further with philosophical proofs of the existence of God. This is enough to show how philosophy approaches the question. Religion uses philosophical concepts and conclusions and goes beyond them to build personal relationships. The Christian religion argues the existence of God on the basis of revelation and experience. The Christian says that he has contact with God and knows that he exists.

The strict behaviorist would reject the evidence that the philosopher, or religionist, or Christian brings on the ground that it is introspective. Any argument to suit him must meet the test of the objective method. Philosophy and religion say that God is spirit. The radical behaviorist says, "I can't observe, touch or see or hear, a 
spirit and my assumption is that what cannot be observed by the physical senses does not exist, therefore God does not exist." At least he would say that the idea of God is a worthless and out of date concept. In like manner would the behaviorist have to reject the religious doctrine of revelation. Everything must accord with the stimulus-response formula. Man can only respond with the physical organism, he has no soul, and so if there were a God man could not receive his revelation. True, God might express his revelation in physical stimuli, but even then man would never know that it came from a spirit.

The only stimulus that Watson recognizes in religion is that of fear. It is the only basis of the relations between God and man, according to his treatment. In fact it is the only support that religion has. He says, "If the fear element were dropped out of any religion, that religion could not long survive."5 But Watson has already said that the fear response is "unlearned behavior." Then religion doesn't build it in when it makes its appeal to man. Watson would probably answer that religion builds upon it. The answer is found at least in the Christian religion, which claims to build upon the foundation of love, saying that "perfect love casts out fear." 6

Religion says that man enters into relations with 
God through faith and trust. The extreme behaviorist would say that he knows nothing of such acts for they cannot be observed. Man doesn't exercise faith with his viscera or glands and so, as all behavior must be expressed in terms of such responses, there can be no such human action as faith. There is, then, no way for the strict behaviorist to enter into relations with, or to observe, God. The only conclusion is that he must be an atheist, or an infidel.

\section{Immortality.}

The third and final problem to be considered here is immortality. It may be just briefly stated. Will man's life continue beyond the grave? Once more science has nothing in the way of explanation or proof to offer. Philosophy can offer only speculation. It is a matter left entirely to religious belief and conviction.

The ethical and religious values that grow out of the doctrine of immortality are of far-reaching importance. It is difficult to overestimate them. Thoughts that center in the world to come have permeated the ethical standards of man the world over and are constantly influencing his conduct.

Since extreme behaviorism rules out the existence of the soul it is evident without further argument that he rejects all forms of belief in immortality. He would 
have to come to such a position from two angles. In the first place he denies that there is anything to man but the physical organism and we know that at death the body disintegrates. In the second place he denies that we can know anything except by outward observation and the only thing that we can observe of a man after his death is the decaying of his body.

In religion, then, the conclusions of behaviorism lead to a denial of the soul, of the existence of God, and of the immortality of man. But it is to be noted that the extreme behaviorist disposes of the problems of religion by arbitrarily brushing them aside. He would take religion from man and of fer him nothing in its place. 


\section{REFERENCES, CHAPTIR VI}

1. The New Testament, The Gospel of John xvil:3.

2. W. G. Everett, "Moral Values," p. $377 \mathrm{f}$.

3. J. B. Watson, "Behavi ori sm," p. 4.

4. Ibid., p. 5 .

5. Ibid., p. 4 .

6. The New Testament, I John iv: 18 . 


\section{CONCIUSION}

I have given my interpretation of the philosophical implications of behavioristic psychology. Many will not agree with me in all of my conclusions, but that is not to be expected. If I have succeeded in pointing out the general philosophical tendencies of behavioriam I have achieved, in part at least, the end that I set out to reach. Perhaps more emphasis has been placed upon the position of the extreme behaviorist than might have been expected, but it has seemed to me that the extreme position indicates the logical tendency of the essential tenets of behaviorism. These lead to a mechanistic and materialistic philosophy; a system of paradoxes and fallacies in logic that could never give uniformity, or consistency, or reliability in thinking; a mechanical reflex system of epistemology that limits the acquirement of knowledge to muscular apprehension; a hedonistic and deterministic ethics on a trial-and-error basis; and to no religion at all, but to a crass materialism.

of course one may be a behaviorist wi thout accepting these extreme views. He may be a moderate behaviorist, and that might mean almost anything from a little more than an introspectionist to a little less than 
a strict behaviorist. It is the privilege of every thinker to examine the behavioristic theory, or hypothesis, in general and in the light of its logical conclusions, and accept what seems to him to be true and reject what seems to him to be false. If one rejects the conclusions but accepts the logic of reasoning that reaches those conclusions, he must also reject the basic assumption from which those conclusions are drawn.

If there were time and space sufficient it would be both interesting and helpful to follow out the implications of each of the types of behaviorism listed in the introductory chapter. If this could be done perhaps it would be found that purposive behaviorism would lead to somewhat different philosophical conclusions from some of these presented in this thesis. Behaviorism of this type refuses to recognize mental or conscious activity, but it does recognize the objectively observable fact that behavior is a goal-seeking process. This is not the extreme position that is championed by Watson and others. But it would be difficult to reconcile it with the denial of conscious activity, for purposive behavior implies the selection of means toward an end, which, in turn, would seem to call for what we have been terming conscious activity. So it would seem that purposive behaviorism would have to lead to extreme behaviorism to be consistent. 
The near behaviorism that McDougall describes would leave the way open for a variety of implications and conclusions. The behaviorists of this group neither deny nor totally ignore the facts of conscious activity, but they refuse to use introspectively observable facts. It is evident that one cannot deal specifically with such an elastic position as this. It would be necessary to consider the views of each individual near behaviorist. This would be interesting but unending.

There will arise other types of behaviorists and their positions will lead to different philosophic conclusions. And so this thesis cannot be said to be complete. The finished and final thesis in philosophy has not been written-perhaps never will be. 


\section{BIBLIOGRAPHY}

Angell, J. R., "Psychology."

Calkins, N. W., "Introduction to Psychology."

Colvin, S. S., and Bagley, W. C., "Human Behavior."

Dewey, John, "How We Think."

Dewey, John, and others, "Creative Intelligence."

Dorsey, G. A., "Why We Behave Like Human Beings."

Durant, Will, "The Story of Philosophy."

Everett, W. G., "Moral Values."

Flewelling, R. T., "Creative Personality."

Gault, R. H., "Outline of General Psychology."

\& D. T. Howard,

Hibben, J. G., "Logic Deductive and Inductive."

Hollingworth, H. I., "The Psychology of Thought."

Holt, E. B., "The Freudian Wish and its Place in Ethics."

Horton, R. F., "The Capacity for God."

James, William, "The Meaning of Truth."

"

"

n

ต

II
" "Pragmatism."

" "Psychology."

" "Some Problems of Philosophy."

" "The Varieties of Religious Experience."

" "The Will to Believe."

Martin, E. D., "Psychology and its Use." 
McDougall, William, "Ethics and Some Modern World Prob-

\section{lems."}

Meyer, Max F., "The Psychology of the Other One."

New International Encyclopaedia.

Palmer, G. H., "The Nature of Goodness."

" " "The Problem of Freedom."

Parmelee, Maurice, "The Science of Human Behavior."

Patrick, G. T. W. , "Introduction to Philosophy."

Perry, R. B., "Present Philosophical Tendencies."

Pillsbury, W. B., "Education as the Psychologist Sees It." "Psychologies of 1925."

Rand, Benjamin, "Modern Classical Philosophers."

Strickland, F. L., "The Psychology of Religious Experience."

Thorndike, E. L., "The Elements of Psychology."

Titchener, E. B., "A Text-Book of Psychology."

Watson, J. B., "Behaviorism."

" " "Psychology from the Standpoint of a

Behaviorist."

Woodworth, R. S., "Dynamic Psycholoey."

" " "Psychology, A Study of Mental Iife." Articles

Bauden, H. H., "The Evolution of Behavior," in Psychological Review, 1919.

Bauden, H. H., "The Presuppositions of a Behaviorist Fsychology," in Psychological Review, 1918. 
Delaguna, Grace A., "Emotion and Perception from the Behaviorist Standpoint," in Psychological Review, 1919 .

Fernberger, S. W., "Behavi orism Versus Introspective Psychology," in Psychological Review, 1922. Frost, E. P., "Cannot Psychology Dispense with Consciousness?" in Psychological Review, 1914. Gregory, J. C., "Three Wi tnesses against Behaviorism," in Philosophical Review, 1922.

Koffka, Kurt, "Perception."

Lashley, K. S., "Behaviorism and Consciousness," in Psychological Review, 1923.

Lovejoy, A. O., "The Paradox of the Thinking Behaviorist," Philosophical Review, 1922.

Mursell, J. I., "The Ontological significance of Instinct, Habit and Intelligence," in Psychological Review, 1922.

Mursell, J. L., "The Stimulus Response Relation," Psychological Review, 1922.

Ogden, R. M., "Are there any Sensations?" in Philosophical Review, 1922.

Pratt, J. B., "The New Materialism," in Journal of Philosophy, 1922.

Roback, A. A., "Intelligence and Behavior," Psychological Review, 1922.

Rogers, A. K., "The Logic of Memory," in Philosophical 
Review, 1922.

Sheldon, W. H., "The Soul and Matter," Philosophical Review, 1922.

Tolman, E. C., "Concerning the Sensation Quality-A Behavioristic Account," in Psychological Review, 1922.

Troland, L. W., "The Significance of Psychical Monism," in Psychological Review, 1922.

Warren, H. C., "Awareness and Behaviorism," in Philosophical Review, 1922.

Watson, J.'B., "A Schematic Outline of the Imotions," in Psychological Review, 1.919.

Weiss, A. P., "The Mind and the Man Within," in Psychological Review, 1919.

Wieman, H. N., "The Nature of Mentality," in Fsychological Review, 1912. 